\title{
Derecho de participación en contextos de cuidado y protección
}

\section{Gloria Marina López ${ }^{1}$, Magaly Rafaela Couret $^{2}$, Yuherqui Ayari Guaimaro \\ Universidad Metropolitana-Cendif-Caracas}

\section{Artículo científico}

Material original autorizado para su primera publicación en el Journal de Ciencias Sociales, Revista Académica de la Facultad de Ciencias Sociales de la Universidad de Palermo.

Recepción: 02-04-2018

Aceptación: 29-08-2018

Resumen: Se examina el derecho de participación aplicado al contexto de cuidado y protección. Es una investigación cualitativa que incorpora un análisis de las significaciones que los y las adolescentes institucionalizados otorgan al proceso de la participación en sus vidas cotidianas. Estudios previos los representan negativamente, protegidos en cuanto a su incapacidad e irresponsabilidad, sin garantizarles sus derechos de participación, y los consideran incapaces de participar y contribuir social y políticamente en sus entornos debido a razones aludidas en términos de falta de habilidades, irracionalidad, inmadurez y dependencia. A través de un cuestionario se accede a la forma en la que interpretan y significan la participación en sus vidas, en tres dimensiones: opinión, toma de decisiones y acción. La experiencia demuestra que conocen de la necesidad que tienen de ser escuchados, de ser tomados en cuenta, de ser parte de las decisiones que los afectan, de tener opciones para elegir y proponer. Además, son capaces de solicitar espacios de participación igualitaria ante los profesionales de la entidad de atención, sus familias (en los casos en que cuentan con ella), y con los otros niños, niñas y adolescentes protegidos con los que comparten el día a día. Asimismo, tienden a buscar espacios de interdependencia que les permitan tomar, gradualmente, sus propias decisiones sin control adulto, ya sea profesional o familiar. El sistema de protección de la infancia en situación de abandono termina por ser una estructura que invisibiliza al protegido y por ser un mediador en los conflictos que derivan de la relación entre profesionales, familias y los propios protegidos, por

\footnotetext{
1 Psicóloga, profesora e investigadora. Directora del Centro de Investigaciones para la Infancia y la Familia (CENDIF) - Facultad de Ciencias y Artes - Universidad Metropolitana, Caracas, Venezuela. Correo electrónico: glopez@unimet.edu.ve.

2 Psicóloga, profesora e investigadora adscrita al Centro de Investigaciones para la Infancia y la Familia (CENDIF) Facultad de Ciencias y Artes - Universidad Metropolitana, Caracas, Venezuela.

${ }^{3}$ Socióloga, profesora e investigadora adscrita al Centro de Investigaciones para la Infancia y la Familia (CENDIF) Facultad de Ciencias y Artes - Universidad Metropolitana, Caracas, Venezuela.
} 
lo que merma el objetivo de la protección en sí y minimiza las oportunidades de participación. Se aborda un tema poco investigado, al aportar una nueva forma de ver y entender el mundo de la protección de los NNA bajo la tutela del sistema de protección.

Palabras clave: adolescentes; institucionalización; participación; protección.

\section{Right of Participation in Care and Protection Contexts}

Summary: This investigation aims to analyze the right to participate related specifically to the notions of care and protection. The research provided here is of a qualitative nature and it also encompasses an analysis of the significance and relevance institutionalized teenagers place on the process of protection during their daily lives. Professionals have a tendency of portraying sheltered teenagers in a negative light, accusing them of an apparent lack of skills and responsibilities. Said professionals will therefore deny them of their rights to participate and consider these teenagers unable to contribute socially and politically speaking in their surroundings, claiming said lack of skills, and supposed lack of rationality and maturity. Through a series of interviews, we inquire about the way kids in need interpret and foresee their life trajectories as sheltered individuals, as well as the opportunities they believe they'll have to develop as legal subjects. Our experiences have shown that these teenagers will exhibit the use of several strategies to ascertain their autonomy, as well as being able to demand, from child welfare professionals and their families (as some may still have them) the opportunity to rightfully have a say on their lives. They show, as well, a tendency to search for places and opportunities to freely make their own decisions without professional or family supervision. Child protection services, usually regarding kids without a home or family, will sometimes become an institution that robs these kids and teenagers of their autonomy and act as a conflict mediator between professionals, the families of the kids (again, in the case of the few who still have them) and the sheltered kids themselves. Since this research tackles a topic with little precedence, it brings about a new way of seeing and understanding the notion of sheltering and protecting kids and teenagers.

Keywords: teenagers; institutionnalisation; participation; protection.

\section{Introducción}

El 20 de noviembre de 1989 la Asamblea General de las Naciones Unidas aprobó la Convención sobre los Derechos del Niño (CDN), primer código universal de los derechos de los niños y las niñas legalmente obligatorio que incluye a todos los menores de 18 años, independientemente del lugar de nacimiento, de quiénes sean sus padres o su familia, de 
cuál sea su sexo, su etnia, la religión que practiquen o la clase social a la que pertenezcan (ONU, 1989).

Para Verhellen (1992) se dio un giro en la representación social de la infancia en el consenso internacional sobre los derechos de los niños y niñas a partir de la CDN de 1989. La Declaración del año 1924 conceptualizó al niño y a la niña como recipiente/objeto de medios, cuidados, socorro, protección y conciencia social. La Declaración de la ONU de 1959 reflejó este mismo concepto, aunque introdujo la no-discriminación y el interés superior del niño. Estos dos principios fundamentan y derivan de la visión de la niñez como participante/sujeto de derechos adoptada por la CDN. Por un lado, una correcta interpretación del derecho a la no-discriminación debería impedir a los adultos excluir a los niños y a las niñas de las decisiones que los afectan y, a su vez, lograr que el interés superior del niño no pueda ser discernido sin su participación.

En América Latina, prácticamente, todos los países en los últimos quince años han reformado sus leyes de infancia para adaptarlas a los mandatos de la Convención, se ha avanzado significativamente en el reconocimiento de los derechos humanos de los niños y las niñas y en la mejora efectiva de sus condiciones de vida.

El paradigma moderno de ciudadanía plantea la igualdad de oportunidades y de derechos para cualquier persona, independientemente de su condición biológica, cultural o socioeconómica, pero en la práctica se observan desigualdades, dado que existen individuos que no acaban de ser incorporados en el debate público. Tal es el caso de los niños y las niñas, considerados como sujetos pasivos, incapaces de participar y contribuir social y políticamente debido a falta de habilidades, irracionalidad, inmadurez y dependencia. En esta categoría se encuentra el caso de los niños y las niñas declarados en desamparo.

Se intenta abordar el tema de la ciudadanía de los niños, niñas y adolescentes (a partir de este momento NNA) en contextos de protección, y aportar en cierta medida una nueva forma de verlo y entenderlo desde la perspectiva de derechos y enfoque de la ciudadanía real e inherente (Invernizzi y Milne, 2005), y ofrecer una nueva forma de verlos y entenderlos al significar los procesos sociales que potencian o inhiben su integración cívica.

El debate sobre los derechos de participación y ciudadanía de los NNA desde la década del 2000, y en consonancia con la Convención de los Derechos del Niño (ONU, 1989), ha sido utilizado como una parte esencial en el diseño de las políticas nacionales e internacionales para la infancia, así como para fundamentar el conocimiento científico de un sinnúmero de investigaciones acerca de la vida de los NNA (Flekkoy y Kaufman, 1997), al presentar a los niños y a las niñas como ciudadanos y actores sociales, competentes para participar activamente en el mundo que les rodea. Sin embargo, los derechos de participación y ciudadanía de los niños y las niñas son limitados o facilitados por condicionantes políticos, 
económicos, sociales y culturales (Lister, 2003), que determinar el significado que adquiere la ciudadanía de acuerdo con el contexto y con cómo se deben interpretar y ejercer los derechos de participación de ambos. La forma en que los derechos de participación y ciudadanía de los niños y las niñas son garantizados depende de cómo se representa a la infancia en situaciones particulares o si entran en conflicto con otros principios como los de protección (Kjorholt, 2008).

En el marco de un avance hacia la comprensión de los mecanismos de transformación social de la participación infantil, nos acercamos al ejercicio del derecho de la participación desde la propia perspectiva de los niños y las niñas, en una entidad de atención que ofrece protección a NNA en riesgo.

\section{Antecedentes}

La República Bolivariana de Venezuela ha ratificado la Convención sobre los Derechos del Niño y sus dos protocolos facultativos. En cumplimiento del artículo 4 de la Convención sobre los Derechos del Niño, el Estado venezolano sancionó y promulgó la Ley Orgánica para la Protección de Niños y Adolescentes (1998), reformada en el año 2007, y avanzado significativamente en la creación de su marco normativo e institucional para la protección de los niños, niñas y los y las adolescentes. Con ello consagró el interés superior del niño como un principio de interpretación y aplicación, de obligatorio cumplimiento.

El Informe Somos Noticia de CECODAP, publicado en el año 2011, reporta que durante el período Octubre 2010 y Septiembre 2011 aumentó en 11\% el número de casos de violencia hacia NNA al registrar 4107 casos en comparación con los 3708 registrados en el período anterior (Octubre 2009 - Septiembre 2010). De los 1492 NNA víctimas, 44\% fue por homicidio, $17 \%$ herido por arma de fuego y un $12 \%$ involucrado en hechos violentos como secuestros, heridas con armas blancas o testigo de un homicidio. De estas víctimas, un $94.8 \%$ de las muertes se produjo como consecuencia de la violencia social: riñas, ajuste entre bandas, robos o tiroteos en la vía pública.

La Fundación Oficina Nacional de Denuncia del Niño Maltratado (FONDENIMA) en Caracas, en el trienio 2007-2012 atendió un total de 453 casos de todos los tipos de maltrato de NNA. El primer lugar se encuentran los casos de maltrato físico (38\%), seguido por abuso sexual (29\%), maltrato psicológico (23\%), negligencia (9\%) y, por último, el Síndrome de Münchhausen o agresión por delegación con $0,5 \%$. Estas cifras reflejan un incremento año a año de casos de abuso sexual.

Por su parte, el Programa de Atención de Niños y Adolescentes en Circunstancias Especialmente Difíciles (PANACED), con sede en la ciudad de Barquisimeto, Estado Lara, 
atendió 2073 casos de maltrato de NNA en el trienio 2010-2012. De acuerdo con la clasificación de UNICEF, de este total un 32,4\% corresponde a Maltrato por (abuso) sexual, seguido por riesgo bio-psico-social (14,9\%), negligencia $(14,3 \%)$, maltrato físico $(11,2 \%)$, intento de suicidio $(6,7 \%)$, maltrato psicológico $(7 \%)$, violencia familiar $(5 \%)$, maltrato escolar/ institucional (3\%), casos de madres adolescentes (2\%) y abandono materno o paterno en el que se reporta un $2 \%$. Al igual que en las cifras aportadas por Panaced, preocupa en especial el alto porcentaje de abuso sexual.

\section{Contexto Venezolano}

Actualmente Venezuela se encuentra afectada por una crisis humanitaria y, según los datos aportados por Encovi (2017), con un 87\% de la población en situación de pobreza. De esa cifra, más de la mitad (el 56\%) es reciente y el $30 \%$ es crónica, a lo que debe agregarse el deterioro del sistema de salud y educativo, con más del $68 \%$ de la población sin seguro de atención médica, y un aumento de las enfermedades infecto contagiosas. A su vez, se observa un aumento de la deserción escolar, un descenso (78\% a 71\%) en el acceso a la educación de la población de 3 a 24 años entre 2015-2017, y la inasistencia escolar por falta de comida. La escasez de alimentos básicos, medicinas y productos de higiene personal se suma al aumento significativo del otorgamiento de medidas de abrigo a menores en estado de desnutrición, un aumento significativo del abandono de niños y niñas recién nacidos, elevados índices de violencia, incremento del desempleo y retardo procesal penal.

\section{Políticas públicas y participación}

Según la Red por los Derechos Humanos de los NNA en su informe sobre la situación de sus Derechos en la República Bolivariana de Venezuela (Redhnna, s/f), el Tribunal Supremo de Justicia acordó en Sala Plena la promulgación de unas orientaciones para garantizar el derecho a la opinión de los NNA. Existe un temor generalizado hacia su participación en espacios informativos y entrevistas y a que el mismo fenómeno opere en otros espacios naturales de desarrollo como la escuela y las comunidades, en los que las instancias de participación de los NNA no existen, por lo que su consulta con respecto a elementos que le conciernen y la expresión de sus opiniones no son parte de las prácticas cotidianas. La Redhnna aporta que vale la pena destacar la Ley de Consejos Comunales, creada para regular el funcionamiento de estas instancias de participación. En ella se contempla el derecho al voto a partir de los 15 años para los y las adolescentes, lo cual, aunque se valora como un avance significativo, excluye el derecho de ambos a participar activamente en los asuntos políticos a nivel local. Este hecho implica una contradicción con 
respecto a la edad establecida para la responsabilidad penal, que rige a partir de los 12 años, al aducir que los y las adolescentes están en la capacidad de asumir responsabilidad penal, pero, a su vez, los califica de incapaces de asumir procesos de participación en los asuntos que le conciernen.

En la CDN (1989) la participación infantil queda explícitamente integrada en los artículos sobre la vida cultural, la discapacidad y los procesos judiciales. Es, sin embargo, el artículo 12 el que concreta el derecho infantil a la participación, donde se hace alusión al derecho de los niños y las niñas a expresar su opinión con libertad en los asuntos que le conciernen y a tomar en cuenta sus opiniones.

La participación del niño y la niña en la determinación de su entorno constituye un elemento fundamental en la formación de su identidad psicológica y social. En este sentido, niñas y niños son ciudadanos en virtud de su derecho a la participación en la articulación de la sociedad, ya que prácticamente todo el entorno social los afecta, directa o indirectamente (Smith y Bjerke, 2009: 15-21).

\section{Protección de la niñez y adolescencia}

Desde el año 1998, con la Ley Orgánica para la Protección del Niño y del Adolescente, se ha intentado establecer un Sistema de Protección que garantice el goce pleno y efectivo de los derechos a todos los NNA. Entre 1998 y 2007 se intentó consolidar un Sistema de Protección inspirado en un modelo para situaciones de amenaza o violación a los derechos de NNA.

Se dispone de un marco normativo para la protección y atención de los NNA como sujetos plenos de derecho, y persisten limitaciones entre lo teórico y lo práctico en lo que respecta a la infancia y la adolescencia. El Sistema de Protección ha estado centralizado en un Ministerio con competencia en la materia de niñez y adolescencia y gestiona sus acciones a través de un instituto autónomo denominado Consejo Nacional de Derechos (IDENA). La inexistencia de una política pública, bien definida y acordada con todos los entes nacionales que deben estar involucrados, no favorece la protección y la garantía de los derechos de los NNA.

A la ausencia de programas de protección y atención se le suma la falta de coordinación y seguimiento de acciones de la sociedad civil y de las familias, tal como lo establece el principio de corresponsabilidad en la Ley Orgánica para la Protección del Niño, Niña y Adolescente (LOPNNA). Hay una falta de capacitación y formación especializada de los profesionales y técnicos vinculados con la garantía de derechos que no solo favorezca el 
respeto por los derechos de los NNA, sino también su eficiente participación con logros medibles en el contacto con la familia, comunidad y escuela.

No se dispone de una base de datos o sistema de información sobre los derechos de los NNA que presente estadísticas e informes oficiales respecto de la situación de sus derechos. Se advierte un uso desmedido de la institucionalización de niños y niñas por razones de protección, pese a que esa medida debería ser utilizada únicamente de modo excepcional.

Es muy preocupante que no pueda establecerse con exactitud cuántos NNA se encuentran en modalidades de cuidado alternativo, y aún más preocupante es no conocer la calidad de la atención que reciben. Se hace necesario que los Sistemas Nacionales de Promoción y Protección de los Derechos del NNA centren mayores esfuerzos en las acciones de fortalecimiento de las capacidades de las familias para la crianza de sus hijos e hijas y para la prevención y detección temprana de situaciones de violencia, abuso y negligencia que vulnera sus derechos. Deben diseñarse y desarrollarse programas de fortalecimiento familiar sobre la base de políticas públicas.

La inexistencia de un criterio único de sistematización dificulta determinar con exactitud avances o retrocesos en la cantidad de niños y niñas y en la calidad del servicio en estos centros, dada la falta de control, seguimiento y de un sistema nacional de información que demuestre la efectividad en el cumplimiento de sus derechos.

\section{Argumentación teórica}

\section{Participación}

La necesidad de participación se ha convertido en un derecho reconocido por instrumentos internacionales que la protegen. Como seres humanos, este derecho también es intrínseco a los niños, niñas, los y las adolescentes. El concepto de participación varía, y cabe mencionar que Allan Dale (1999) la define como la capacidad real, efectiva del individuo o de un grupo, de tomar decisiones sobre asuntos que directa o indirectamente afectan sus actividades en la sociedad y, específicamente, dentro del ambiente en que se desenvuelve. Corona y Morfín (2001) la asocian como un componente de la educación, donde esta puede constituir un importante aporte a la democracia y a la construcción de una cultura de derechos en la convivencia diaria, porque es allí donde se refleja y se construye paulatinamente el orden de la sociedad. Es muy común que se perciba a la participación como algo natural que debe mantenerse y, sin embargo, este es uno de los ámbitos privilegiados para modificar y construir relaciones que transformen el conjunto social. Para Zanabria, Fragoso y Martínez (2007) participar significa una forma de convivencia con los otros incluyendo a todos los que 
nos rodean. Tiene que ver con buscar y obtener información, proponer, expresar e intercambiar muchas cosas: afectos, sentimientos, ideas, intereses, etc., en un ambiente de libertad y de respeto durante la vida cotidiana.

Crowley (1998) define la participación infantil como un principio director clave, un derecho facilitador, que contribuye a asegurar el cumplimiento de todos los demás derechos. Save the Children (en Espinar, 2002) recoge una mirada distinta sobre la participación de niños y niñas a partir de la visión que ellos tienen y de las diversas formas participativas en las que están involucrados. Además, considera que no solo implica que puedan expresar libremente opiniones, pensamientos, sentimientos y necesidades, sino que estos puntos de vista expresados deben ser igualmente tenidos en cuenta por los adultos e influir en las decisiones que se toman, lograr estar involucrados democráticamente por sus familias, la escuela, los gobiernos locales, organismos gubernamentales y no gubernamentales (Save the Children, 2004).

Para que la participación sea verdadera, esta debe implicar que los adultos escuchen aquello que los niños y niñas opinan y que sus opiniones realmente influyan en las decisiones que se tomen. Se trata de generar una cultura de participación a partir de la cual ambos puedan reclamar activamente sus derechos (Liebel, 2007). Desde aquí surge la escalera de participación propuesta por Roger Hart (1993), quien guía sobre el papel real y el valor dado a la opinión de los niños, niñas, los y las adolescentes en el proceso. A partir de esta propuesta, y considerando el rol de los NNA como entes activos, en diferentes momentos, edades, escenarios y el crecimiento en la práctica de la participación, es que podemos entenderla como algo dinámico, circular, flexible y adaptable al contexto y circunstancias.

La definición de participación de Hart (1992) está relacionada con la condición de ciudadanía que tienen los niños y las niñas y que se visibiliza a través de su intervención en las decisiones sobre lo que les afecta individualmente y en el entorno en el que habitan. Se enfatiza la idea de proceso y vía para construir la democracia como modo de vida y gobierno, por lo que sirve, además, como criterio o medida para evaluar la calidad de un sistema que se quiera denominar democrático. En ese sentido, la noción de participación infantil está más vinculada con la idea de participación ciudadana.

Hart (1992) nos presenta las diferentes fases de la participación infantil como peldaños, en donde los tres inferiores corresponden a espacios donde no existe realmente una participación activa de los niños y las niñas y los cinco superiores representan escenarios con participación real y efectiva, desde acciones iniciadas por los adultos, pero con decisiones compartidas con los niños y con las niñas, hasta acciones iniciadas y dirigidas por los propios niños y niñas, quienes conciben y llevan a la práctica proyectos complejos y toman decisiones que les afectan a ellos y a su entorno. 
Jaume Trilla y Ana Novella (2001) proponen la siguiente clasificación: simple, consultiva, proyectiva y metaparticipación. En estos niveles, se exige el reconocimiento de que los NNA que disfrutan del derecho de participación tengan capacidad de decisión y, a la vez, puedan asumir compromisos y responsabilidades cuando ejercen la participación proyectiva donde ellos mismos llegan a proponer las acciones y además las protagonizan.

El informe sobre el Estado Mundial de la Infancia (Unicef, 2003) aborda en profundidad la participación infantil y se señalan algunos de los mitos alrededor de la misma, como ser que los niños y niñas deben ser solo niños y niñas, y que no se les debe obligar a hacerse cargo de responsabilidades que les corresponden a los adultos. Es cierto que en ningún caso dejan de ser niños y niñas y que deben recibir la protección necesaria para garantizar su desarrollo integral, pero también es cierto que no se les debería obligar a asumir responsabilidades para las que no están preparados.

Esto corrobora la tesis de que las habilidades de la práctica democrática no se adquieren al nacer sino, por el contrario, se aprenden, y que en esta medida los procesos de participación se constituyen en un generador de la ciudadanía juvenil en el marco de un mundo ya construido pero en proceso continuo de ser moldeado y transformado, en el que los NNA interactúan con otros actores permanentemente y además deben hacerlo para lograr que su accionar no se quede en esfuerzos sin impacto real (Acosta y Barbosa 2005).

El desarrollo integral de la infancia depende de que se les permita relacionarse con el mundo, tomar decisiones de manera independiente y hacerse cargo de más y mayores responsabilidades a medida que sean más capaces de hacerlo. Cuando los NNA tropiezan con barreras que obstaculizan su participación pueden sentirse frustrados o caer en la apatía, y lo más probable es que terminen por carecer de la experiencia de la participación y que lleguen a ser ciudadanos que no estén adecuadamente preparados para asumir las responsabilidades que le son propias en una sociedad democrática.

\section{Protección}

El contexto actual ubica a la infancia y adolescencia en zonas de vulnerabilidad, y recurre en ocasiones a la institucionalización como una modalidad de protección. La Red Latinoamericana de Acogimiento Familiar (RELAF, 2010), en el Informe Latinoamericano sobre Situación de niñez sin cuidado parental o en riesgo de perderlo, describe que una de las características por las cuales los y las adolescentes ingresan a hogares de abrigo y protección son los factores sociales y culturales vinculados con la pérdida de cuidados parentales, la falta de acceso a la salud, dificultades de acceso a la vivienda, trabajo infantil, esclavitud, explotación sexual y comercial, tráfico de personas, dificultad o falta de acceso a 
la educación, adicciones de los adultos de la familia, abusos y la violencia intrafamiliar. Esta última está ubicada dentro de las primeras causas de pérdida de los cuidados parentales en todos los países de la región.

La familia ocupa el primer lugar donde los NNA aprenden a participar, a conocer sus derechos y a respetar los derechos de los otros. En ocasiones, pasa de ser el entorno protector a convertirse en el lugar donde presencian o sufren la violencia, lo que resultaría en un detonante para que terminen con comportamientos agresivos y/o en la calle (UNICEF, 2008). Es elemental que los NNA puedan disponer de la información acerca del rol y los efectos de su participación, el contexto para sus opiniones y las opciones e implicaciones de esta. Los adultos deberán aceptar sus decisiones, generar espacios de participación, tomar en cuenta sus opiniones y darles la seguridad de ser ellos mismos. La instalación de este espacio y el reconocimiento de los NNA como sujetos debe darse desde el diálogo de saberes entre los distintos actores involucrados en los temas de infancia y convivencia (Carli, 2012).

Una vez que los NNA son considerados como sujeto de derechos se trascienden los límites del ámbito jurídico, lo que se transforma en un punto de partida para el valor que los adultos tienen del lugar de ellos y ellas en la sociedad (Laje y Cristini, 2010). La especie humana es la más ecológica de todas porque se conforma gracias a la interacción entre la genética, la cultura y la participación directa de cada sujeto (Acosta, 2007).

\section{Los y las adolescentes institucionalizados}

En la Convención de Derechos del Niño (1989) encontramos los artículos 9 y 20, los cuales hacen referencia al derecho de los niños y las niñas a no ser separados de sus padres y a aquellos que deben ser privados temporal o permanentemente de su medio familiar, respectivamente. El artículo 9 refiere que los Estados Partes velarán porque el niño y la niña no sean separados de sus padres contra la voluntad de estos, excepto cuando, a reserva de revisión judicial, las autoridades competentes determinen que tal separación es necesaria en el interés superior del niño y agrega que se ofrecerá a todas las partes interesadas la oportunidad de participar y de dar a conocer sus opiniones (CDN, 1989, p. 12).

Por otro lado, el artículo 20 versa sobre los niños y las niñas que se encuentran temporal o permanentemente privados de su medio familiar o cuyo superior interés exija que no permanezcan en ese medio, para que tengan derecho a la protección y asistencia especiales del Estado, el cual le garantizará otros tipos de cuidado, entre esos, la ubicación de los niños y las niñas en hogares de guarda o la adopción. Al considerar las soluciones, se prestará particular atención a la conveniencia de que haya continuidad en la educación del niño y de la niña a su origen étnico, religioso, cultural y lingüístico (CDN, 1989, p. 17). 
Según Viñar (2009) el término adolescencia surge para nombrar una etapa evolutiva que es posible de comprender y estudiar según el marco societario en que esta se desarrolle y transite. No es sino a partir del siglo XVIII que se sucedieron una serie de cambios y avances al reconocer el valor específico de los NNA. Y recién, a partir del siglo XIX, el estudio sistemático de la conducta infantil despertó un interés científico (Zanabria, Fragoso y Martínez, 2007).

Dentro del paradigma de protección integral, se considera que los NNA deben ser considerados en todo lo que concierne a la toma de decisiones e implementación de acciones. Estas deben estar enfocadas en preservar y promover su desarrollo integral sin discriminaciones de ningún tipo. Se debe promover el respeto por los vínculos y dejar de lado la vieja práctica de encerrarlos tal como se realizaba desde el paradigma tutelar. Se pasa a considerar a la familia y a la escuela como las instituciones adecuadas para desarrollar los procesos de socialización (Pilotti, 2004).

El desafío que se plantea en nuestras sociedades con los NNA no es la estigmatización, no es impedir, evitar, alejar un daño o peligro, sino aceptar las diferencias, ampliar los espacios de decisión, de diálogo y de construcción colectiva en la que encuentren su lugar desde sus particularidades y anhelos (Konterllnik, 2000).

Hammarberg (1998) considera que, para lograr una verdadera transformación, se requerirán profundos cambios de actitud, métodos de enseñanza y de filosofía del sistema social, siempre teniendo en cuenta que una de las maneras de estimular esos cambios es estrechar los vínculos entre el sistema educativo, la familia y la comunidad.

\section{Aspectos metodológicos}

Objetivo: Investigar desde la perspectiva de los y las adolescentes institucionalizados el derecho de participación aplicado al contexto de cuidado y protección.

Es fundamental el abordaje de sus necesidades emocionales, cognitivas y sociales para crear espacios de escucha y participación activa en las situaciones que los involucran y favorecer su adecuado desarrollo integral hacia la etapa adulta y para sentar las bases de la implementación de un "Plan de autonomía" para aquellos y aquellas adolescentes en los que no ha sido posible la reinserción familiar.

Muestra: 13 sujetos adolescentes institucionalizados con edades comprendidas entre 12 y 16 años, con un promedio de edad de 14,3; ocho (8) pertenecientes al sexo femenino $(61,5 \%)$ y cinco $(5)$ al sexo masculino $(38,4 \%)$.

Instituto de protección: Hogar Bambi Venezuela es una asociación civil de carácter privado, sin fines de lucro, cuya Misión es ofrecer afecto y atención integral de excelencia, a 
niños y jóvenes entre 0 y 18 años, privados de su medio familiar, ofreciéndoles un hogar con bases estables para crecer y orientar a la familia biológica o adoptiva, para reinsertar al niño al medio socio-familiar en condiciones seguras y estables. Esta entidad de atención recibe a NNA que han sido objeto de una medida de abrigo o colocación por parte de un Consejo de Protección o un Tribunal de Protección del Estado venezolano, respectivamente. Atiende a 110 NNA privados de su medio familiar, los cuales pasan a vivir temporalmente en el Hogar, hasta tanto se solvente la causa de su intervención y puedan reinsertarse de nuevo a su grupo familiar, o ser dados legalmente en colocación familiar o en adopción por las autoridades competentes. Los y las adolescentes son 15, 7 de sexo masculino y 8 de sexo femenino, alojados en dos de sus sedes, con una organización similar a la de familia sustituta. Están escolarizados, asisten a sus centros de enseñanza por sus propios medios, y reciben una mesada para sus gastos de transporte y personales y una atención médico-pediátrica, odontológica, psicológica, psicopedagógica y asistencia social y legal.

Método: Indicadores de participación infantil - Save the Children Suecia (2002).

Se estructura a partir de entender a la participación infantil como el ejercicio del poder que tienen los niños y las niñas a través de su derecho a opinar e intervenir con otros en la toma de decisiones en los asuntos que afectan sus vidas (indicadores de resultado) y, al mismo tiempo, mostrar las condiciones que permiten una participación que reconoce a los niños y a las niñas como sujetos de derechos (indicadores de proceso) (Save the Children, en Espinar, 2002).

La propuesta de Save the Children comprende un número no extenso de indicadores, de tal manera que puedan ser aplicados en su conjunto, y, simultáneamente, sirvan como marco para el diseño de indicadores según los espacios y experiencias de participación de niños y niñas.

A continuación, se enuncian los indicadores propuestos:

i. Indicadores sobre el derecho a opinar:

OPINIÓN: Manifestación del derecho de los niños y niñas a expresar su punto de vista de forma personal o grupal en determinados asuntos sobre los que tienen información y que esperan, sean tomados en cuenta en los procesos de toma de decisiones que afectan sus vidas. 


\begin{tabular}{|c|c|}
\hline $\begin{array}{c}\text { INDICADORES DE } \\
\text { PROCESO }\end{array}$ & $\begin{array}{c}\text { INDICADORES DE } \\
\text { RESULTADO }\end{array}$ \\
\hline $\begin{array}{c}\text { La opinión de los niños y niñas como: } \\
\text { Expresión de su satisfacción o }\end{array}$ & $\begin{array}{c}\text { La opinión de los niños y niñas es: } \\
\text { insatisfacción. }\end{array}$ \\
Opinión informada sobre & mecanismos de diálogo con otros. \\
asuntos que afectan sus vidas. & Entregada a los que toman \\
Opinión reflexionada sobre & decisiones. \\
asuntos que afectan sus vidas. & Opinión que llega de modo \\
Expresión de reconocimiento & completo al espacio de toma de decisión. \\
personal o grupal. & Tomada en cuenta por los que \\
Opinión reconocida por ellos & toman decisiones. \\
(as) mismos (as) y por los adultos & \\
como un derecho.
\end{tabular}

ii. Indicadores sobre la toma de decisiones:

TOMA DE DECISIONES: Capacidad que tienen los niños y las niñas para acceder directa o indirectamente a espacios donde puedan proponer y elegir con otros, entre un conjunto de alternativas u opciones, aquellas que favorecen su interés superior.

\begin{tabular}{|c|c|}
\hline $\begin{array}{l}\text { INDICADORES DE } \\
\text { PROCESO }\end{array}$ & $\begin{array}{l}\text { INDICADORES DE } \\
\text { RESULTADO }\end{array}$ \\
\hline $\begin{array}{l}\text { Los niños y las niñas: } \\
\text { Cuentan con información } \\
\text { suficiente y oportuna. } \\
\text { Proponen y cuentan con una } \\
\text { diversidad de opciones para elegir. } \\
\text { Son consultados(as) y se } \\
\text { toma en cuenta sus opiniones. }\end{array}$ & $\begin{array}{l}\text { Los niños y las niñas: } \\
\qquad \text { Cuentan con espacios y } \\
\text { mecanismos de toma de decisiones. } \\
\qquad \text { Toman decisiones } \\
\text { directamente sobre los asuntos que } \\
\text { afectan sus vidas. } \\
\text { Toman decisiones } \\
\text { indirectamente sobre los asuntos } \\
\text { que afectan sus vidas. }\end{array}$ \\
\hline
\end{tabular}




\begin{tabular}{|l|l|}
\hline $\begin{array}{c}\text { Eligen los procedimientos } \\
\text { para tomar decisiones. }\end{array}$ & $\begin{array}{c}\text { Los asuntos sobre los que se } \\
\text { Eligen a sus representantes } \\
\text { ante los espacios de decisión. }\end{array}$ \\
Se reconocen en las & interés superior del niño. \\
decisiones tomadas. & \\
Se responsabilizan de sus & \\
propias decisiones. & \\
\hline
\end{tabular}

iii. Indicadores sobre la participación en la acción:

ACCIÓN: Conjunto de actividades y proyectos discutidos, decididos e impulsados por los niños y las niñas que reflejan sus opiniones y su interés por los asuntos que los(as) afectan o conciernen.

\begin{tabular}{|c|c|}
\hline \multicolumn{1}{|c|}{$\begin{array}{c}\text { INDICADORES DE } \\
\text { PROCESO }\end{array}$} & \multicolumn{1}{c|}{$\begin{array}{c}\text { INDICADORES DE } \\
\text { RESULTADO }\end{array}$} \\
\hline $\begin{array}{c}\text { La acción: } \\
\text { Refleja el modo de pensar y } \\
\text { sentir de los niños y las niñas. } \\
\text { Es producto de una decisión } \\
\text { personal y colectiva de los niños y las } \\
\text { niñas. }\end{array}$ & $\begin{array}{c}\text { La acción: } \\
\text { Refleja los asuntos de } \\
\text { Busca cambiar un derecho y las niñas en asuntos } \\
\text { núblicos. }\end{array}$ \\
afectado. & Tiene un carácter político las niñas. \\
Refleja el sentido de & definido. \\
pertenencia al grupo u organización. & \\
\hline
\end{tabular}

Recolección de datos: Comprende un instrumento (validado por 3 árbitros expertos en la temática) dirigido a los y las adolescentes institucionalizados donde se solicita el grado de acuerdo en una escala Likert de 0 a 4 (5 opciones de escogencia) con 20 ítems de modo interrogante que investigan acerca de la participación centrada en tres dimensiones: opinión, 
toma de decisiones y acción. También comprende 3 preguntas abiertas donde se explora cuáles buenas prácticas de participación les ha ofrecido la institución, qué propuestas ofrecen los y las adolescentes para que la institución las incorpore como prácticas de la participación y cuáles serían sus temas de interés para trabajar en un plan de desarrollo personal.

\section{Presentación y Análisis de los Resultados}

A continuación, se presentan los resultados obtenidos a través del cuestionario aplicado a 13 sujetos adolescentes institucionalizados. Los ítems están relacionados con tres componentes claves, la Opinión, Toma de Decisiones y la Acción.

Los resultados se representan en gráficos de líneas, en donde la línea demarcada en color azul representa las frecuencias (Fr) y la línea demarcada en color rojo representa los porcentajes (\%).

\section{Componente Opinión:}

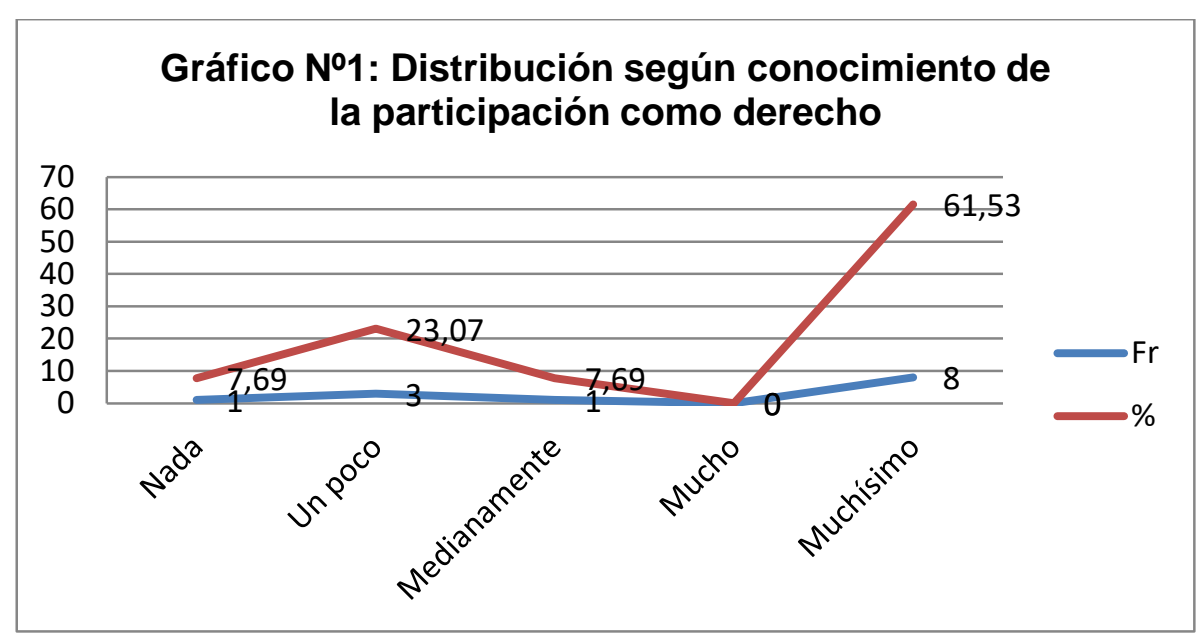

En el gráfico 1 se observa que el $61,53 \%$ (8 sujetos) afirmó tener muchísimo conocimiento de que la participación es un derecho, 3 sujetos $(23,07 \%)$ reportaron solo tener UN POCO de conocimiento, 1 sujeto $(7,69 \%)$ dijo conocer medianamente que era derecho y en la misma proporción manifestó que no sabía que la participación se consideraba un derecho. 


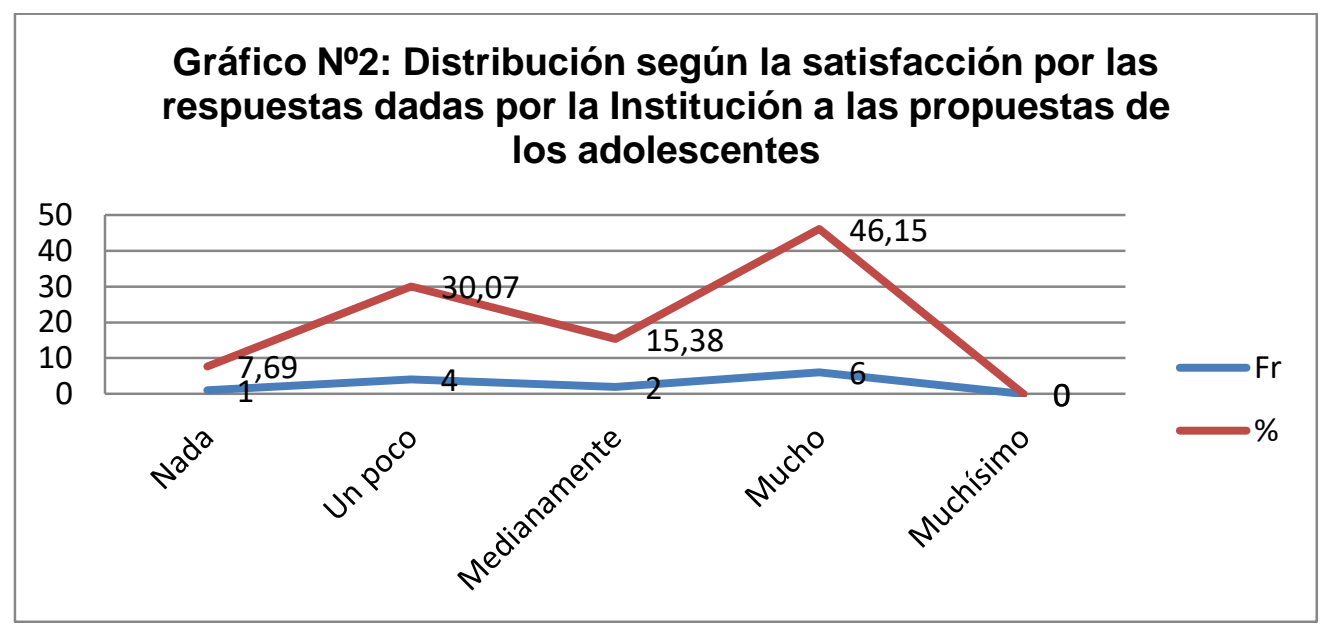

En el Gráfico 2 se reporta que el $46.15 \%$ de los y las adolescentes alegaron sentirse satisfechos por las respuestas dadas por la institución a sus propuestas, calificando el nivel de satisfacción en la categoría MUCHO. Un 15.38\% (2 sujetos) calificaron su nivel de satisfacción en la categoría MEDIANAMENTE, el 30.07\% (4 sujetos) lo calificaron en la categoría UN POCO y un sujeto (7.69\%) manifestó no encontrarse nada satisfecho con las respuestas por parte de la institución a sus propuestas.

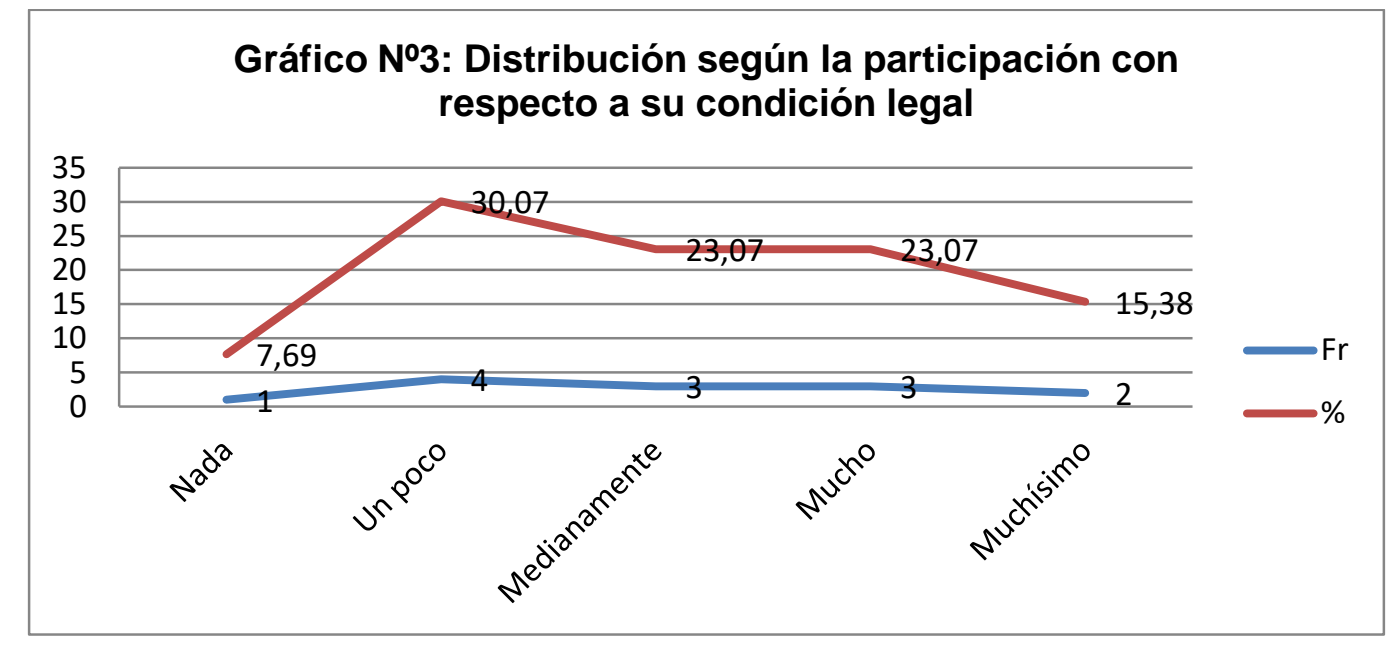

En el gráfico 3 se observa que, del total de la muestra, 5 sujetos $(38.45 \%)$ reportaron que tenían mucha (23.07\%) y muchísima (15.38\%) participación de la información sobre su condición legal y un 53.14\% (7 sujetos) afirmó que participó medianamente (23.07\%) y un poco $(30.07 \%)$ respecto a la información que se refiere a su situación legal. Un sujeto $(7.69 \%)$ alegó no tener ninguna oportunidad de participación en lo que respecta a su circunstancia legal en la que se encuentra. 


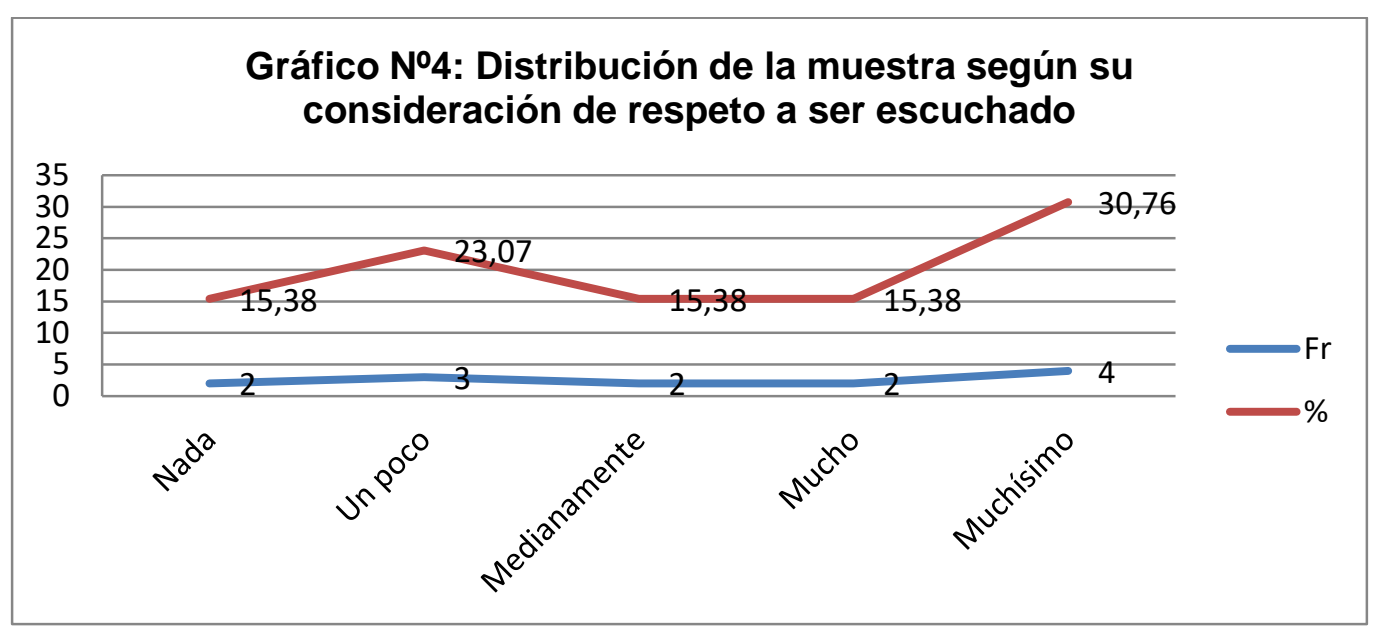

Se observa en el gráfico 4 que un $46.14 \%$ (6 sujetos) consideraron que son escuchados en grado mucho (15.38\%) y muchísimo (30.76\%), un $15.38 \%$ (2 sujetos) calificó el respeto a ser oído con la categoría MEDIANAMENTE, un $23.07 \%$ (3 sujetos) lo reportaron en la categoría UN POCO y 2 sujetos (15.38\%) afirmaron que no ha existido ninguna consideración de respeto a ser escuchado dentro de la institución.

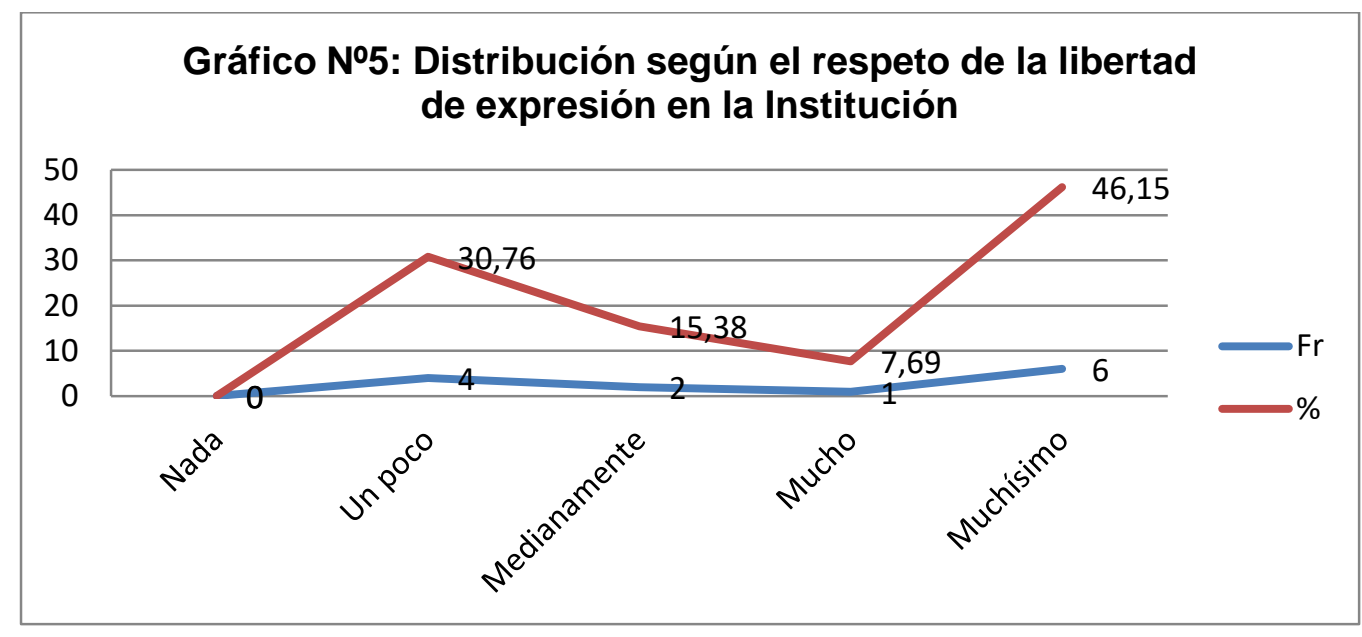

El $53.84 \%$ de los sujetos, que corresponde a 7 del total, consideraron que en la institución se ha estado respetando su libertad de expresión, quedando distribuidos en 7.69\% para la categoría MUCHO y 46.15\% para la categoría MUCHISIMO. Por el contrario, 6 sujetos del total, que corresponde al $46.14 \%$, calificaron en las categorías MEDIANAMENTE (15.38\%) y UN POCO (30.76\%) el respeto a su libertad de expresión. 


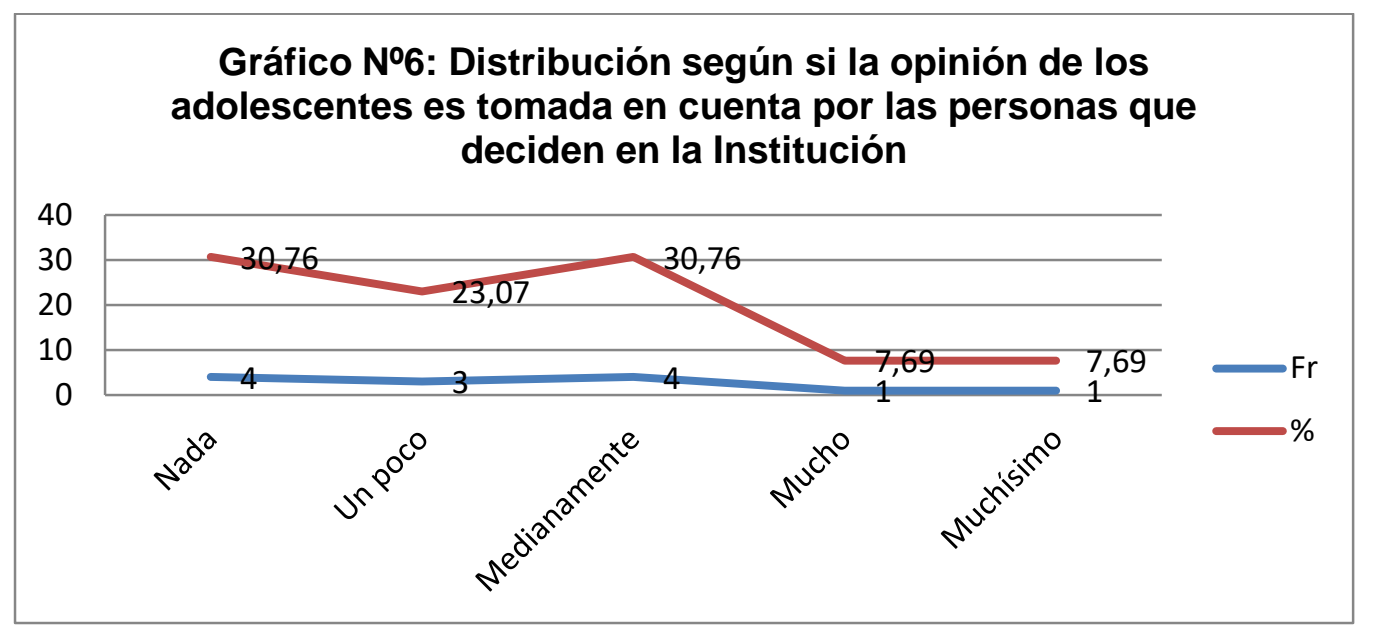

Se visualiza en este gráfico ( $\left.\mathrm{N}^{\circ} 6\right)$ que tan solo 2 sujetos $(15.38 \%)$ consideraron que su opinión había sido tomada en cuenta por las personas que tienen el rol decisorio en la institución. Por el contrario, 7 (53.83\%) de los y las adolescentes manifestaron que su opinión era medianamente y poco tomada en cuenta por los directivos, superando este puntaje al $50 \%$, y 4 de los sujetos (30.76\%) declararon que nunca estas personas habían sido tomada en cuenta su opinión.

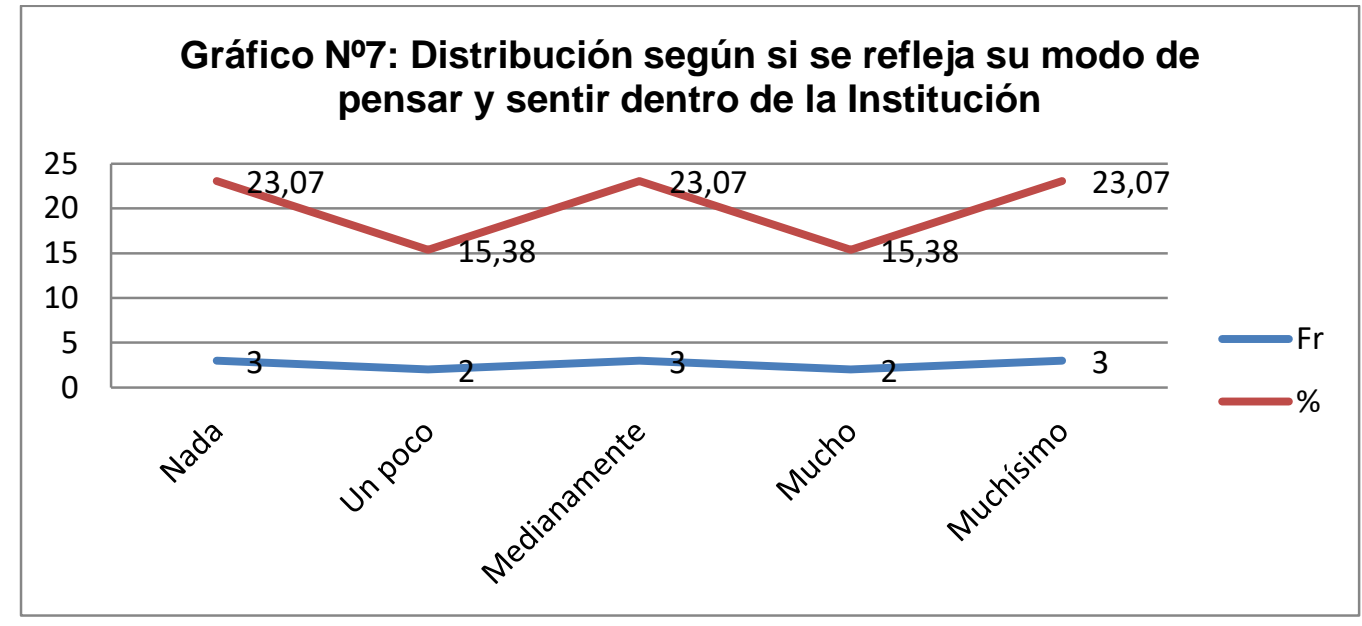

Para el $38.45 \%$ de los y las adolescentes (5 sujetos) sí se ha reflejado su modo de pensar y sentir dentro de la institución. Contrasta esta afirmación con lo que manifestaron los sujetos restantes, puesto que un $38.45 \%$ declaró que su pensar y sentir se ha evidenciado de manera mediana (23.07\%) y poca (15.38\%), y agregan los 3 sujetos $(23.07 \%)$ restantes que para ellos la institución no ha proyectado en nada sus pensamientos ni sentimientos. Ver gráfico №7.

Las respuestas de los y las adolescentes consultados revela que si bien la mayoría conoce que la participación es un derecho, se sienten escuchados y se respeta su libertad 
de expresión, cuando se trata de que esa opinión sea tomada en cuenta para asuntos relaciones con su cotidianidad, esta no es totalmente reconocida por los adultos.

\section{Componente Toma de Decisión:}

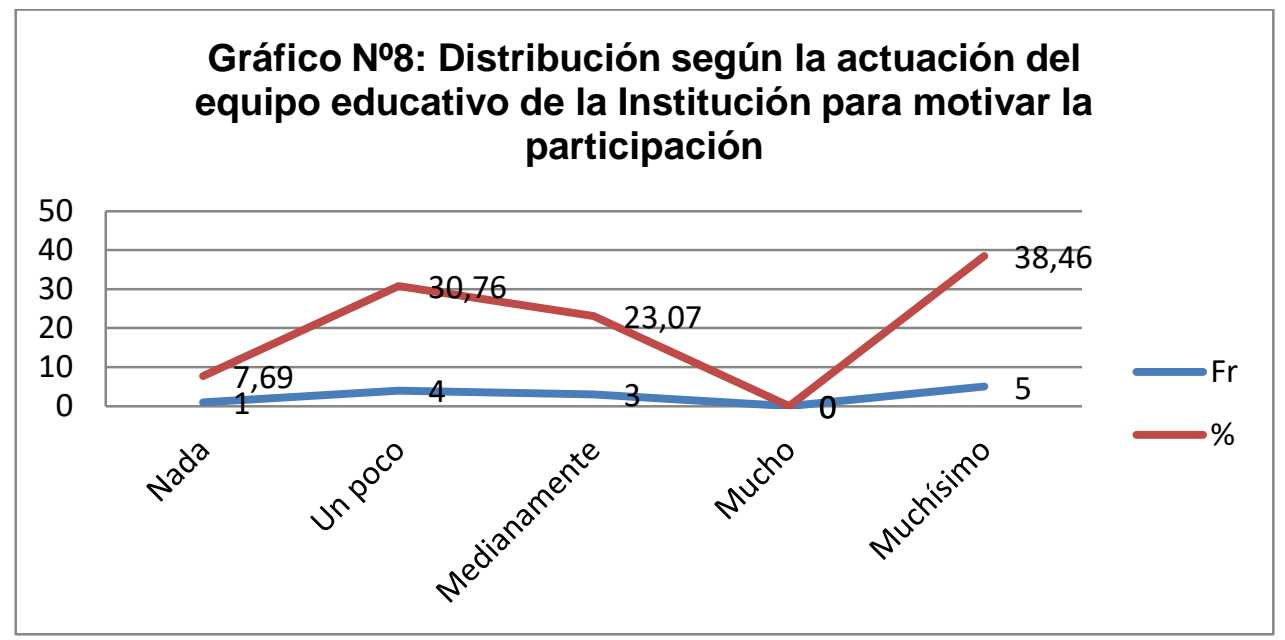

En el gráfico 8 observamos que el $38.46 \%$ (5 sujetos) de los y las adolescentes consideraron que el equipo educativo de la institución ha estado motivando muchísimo la participación, un 23.07\% (3 sujetos) calificaron esa motivación en la categoría MEDIANAMENTE y 4 sujetos (30.76\%) afirmaron que los han estado motivando solo un poco. Un sujeto $(7.69 \%)$ consideró que la motivación para la participación de parte del equipo educativo ha sido nula.

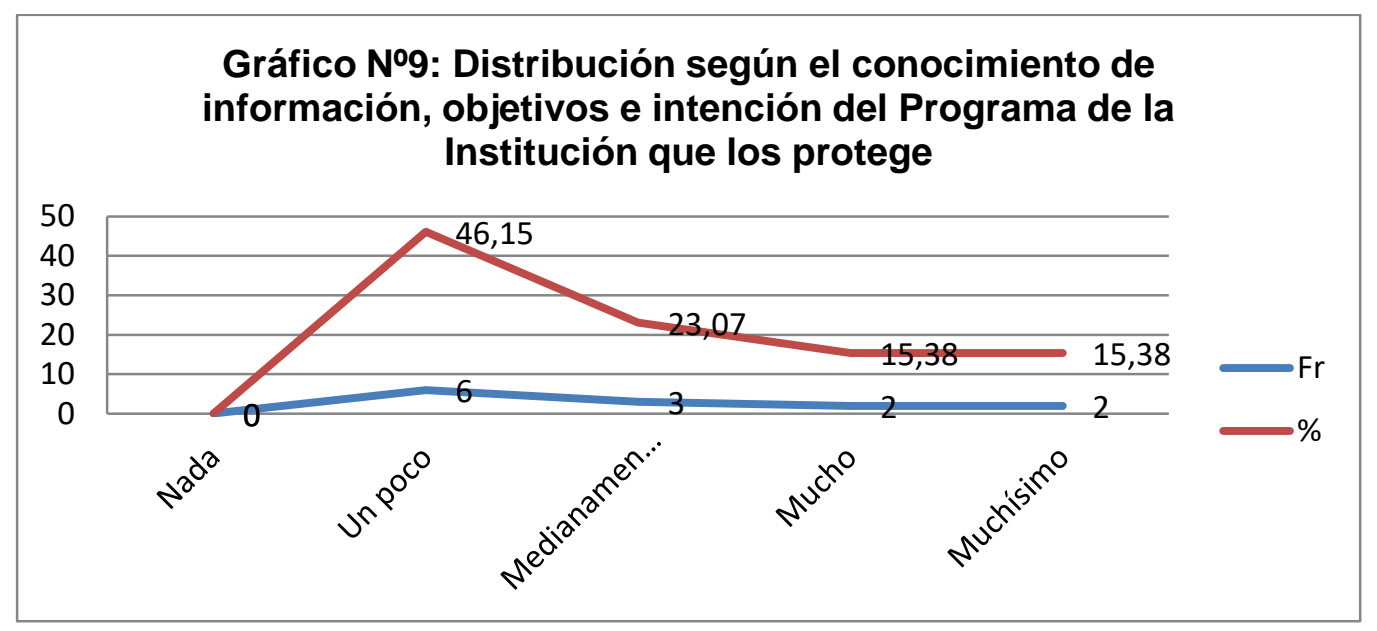


El gráfico 9 reporta que 4 sujetos (30.76\%) afirmaron haber estado informados acerca de los objetivos e intención del programa de la institución que los ha estado cobijando, distribuidos en $2(15.38 \%)$ sujetos para la categoría MUCHO y $2(15.38 \%)$ para la categoría MUCHÍSIMO. Por el contrario, el $69.22 \%$, que corresponde a un total de 9 sujetos, reportaron no haber tenido ningún conocimiento sobre el tema, $3(23.07 \%)$ se ubicaron en la categoría MEDIANAMENTE y 6 (46.15\%) en la categoría UN POCO.

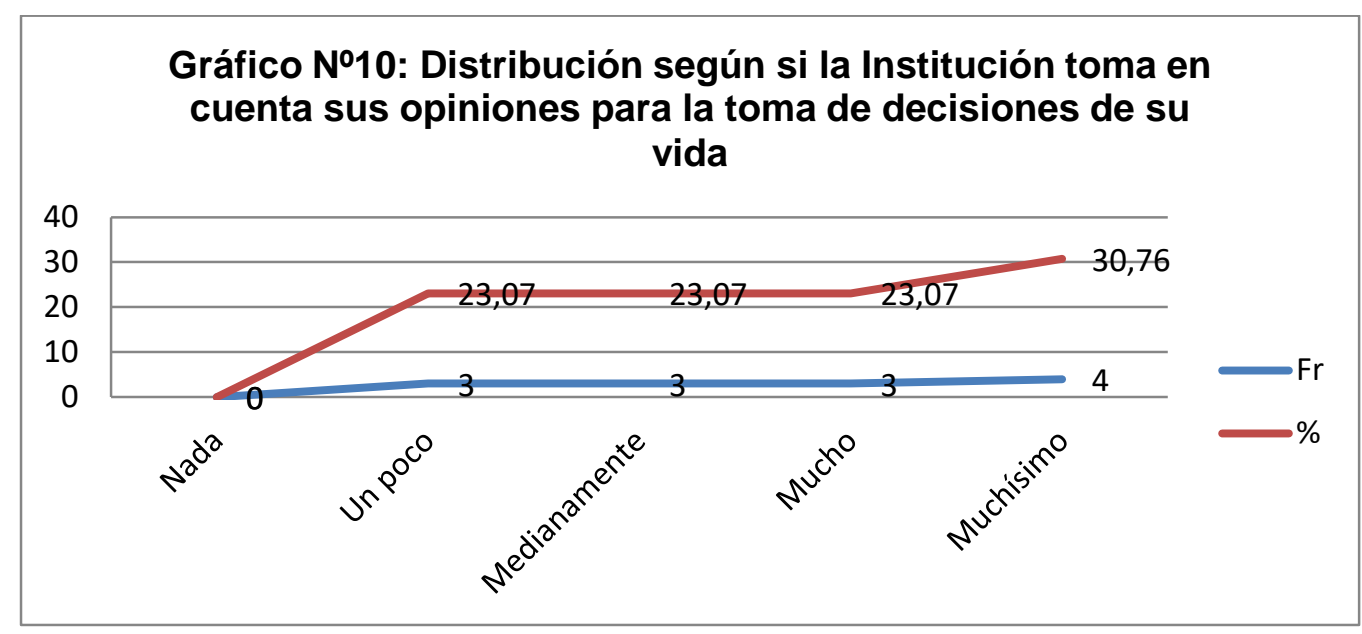

El 53.83\% de los y las adolescentes reportaron que la institución que los protege sí toma en cuenta su opinión para la toma de decisiones en lo que a su vida respecta. Este porcentaje quedó distribuido en 4 sujetos (30.76\%) para la categoría MUCHÍsIMO y 3 sujetos (23.07\%) para la categoría MUCHO. Contrariamente, 6 de los sujetos (46.14\%) calificaron a la institución como responsable de no tomar muy cuenta sus opiniones, clasificándola en las categorías MEDIANAMENTE (23.07\%) y UN POCO (23.07\%) (Ver Gráfico 10).

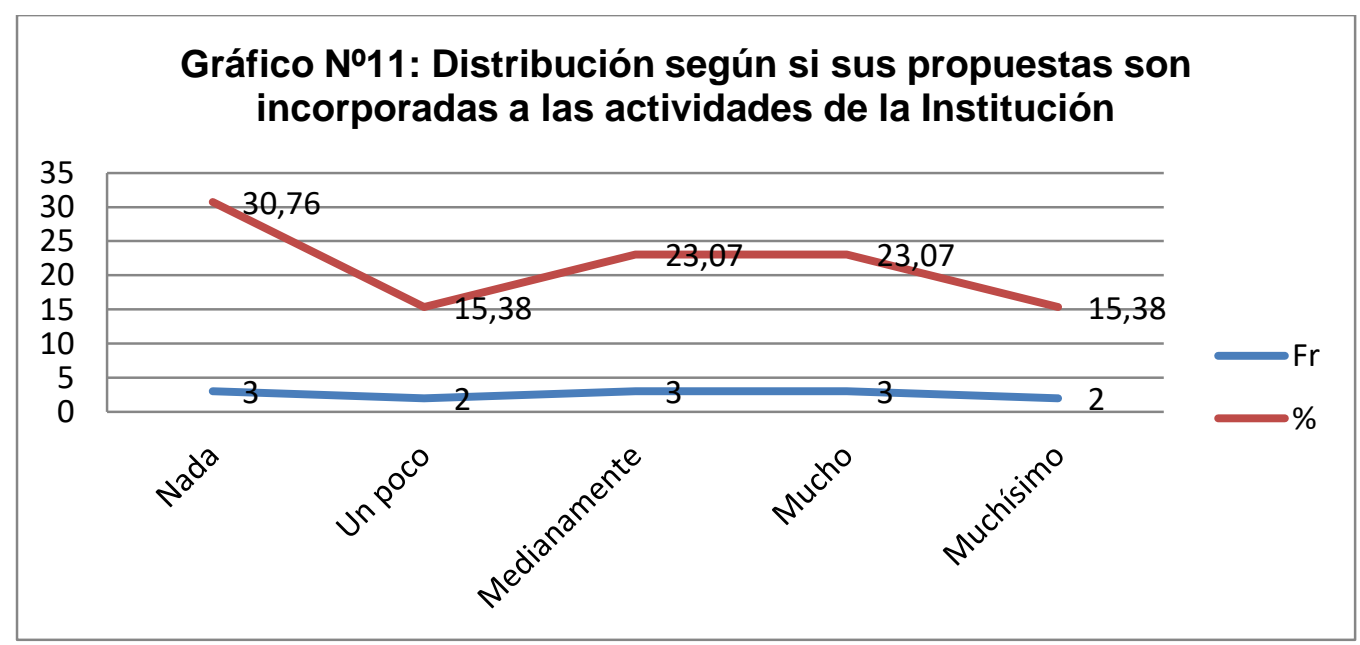


En este gráfico ( $\left.N^{\circ} 11\right) 5$ de los sujetos, de un total de 13, reportaron que la institución sí ha estado incorporando sus propuestas a las actividades que ha programado para los NNA bajo su tutela, 3 sujetos (23.07\%) lo reportaron en la categoría MUCHO y 2 en la categoría MUCHÍSIMO. El 38.45\% (6 sujetos) declaró que sus propuestas han sido tomadas en cuenta solo de manera mediana y poca. Y 3 de los y las adolescentes, que corresponde al $30.76 \%$, manifestaron que nunca han tomado en cuenta sus propuestas para la programación institucional dirigida a los NNA.

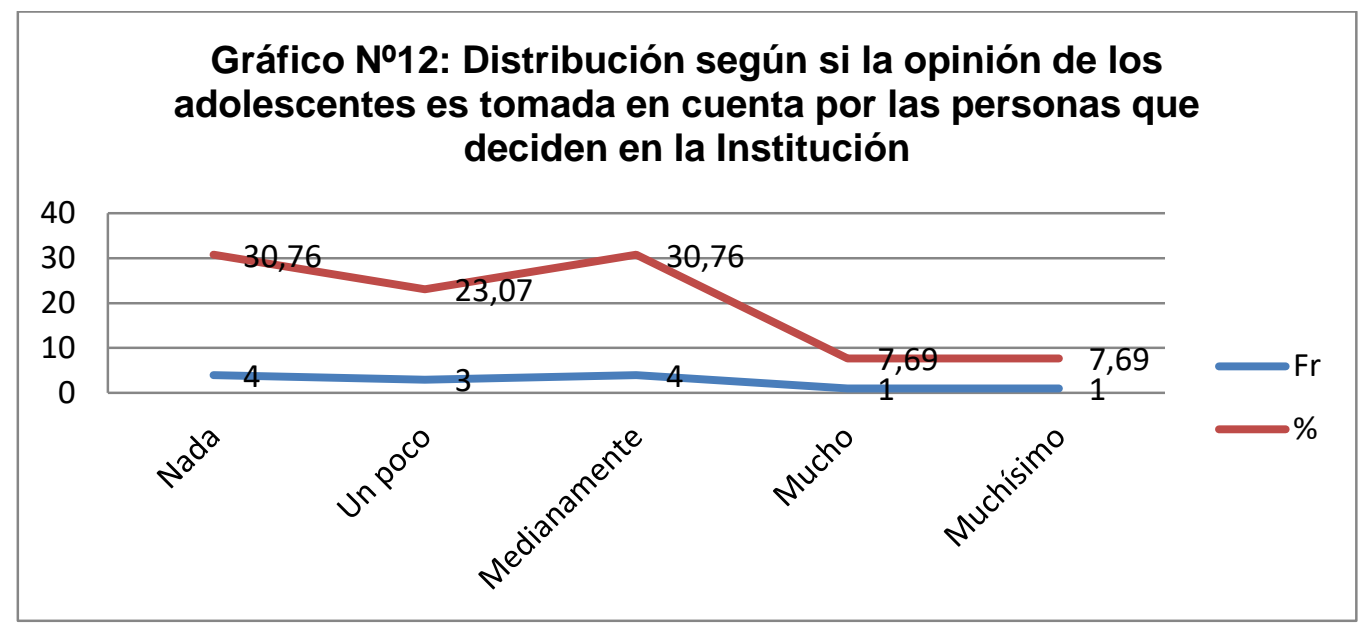

Se visualiza en este gráfico ( $\left.N^{\circ} 12\right)$ que tan solo 2 sujetos $(15.38 \%)$ consideraron que su opinión había sido tomada en cuenta por las personas que tienen el rol decisorio en la institución. Contrariamente, 7 (53.83\%) de los y las adolescentes manifestaron que su opinión era medianamente y poco tomada en cuenta por los directivos, y 4 de los sujetos $(30.76 \%)$ declararon que la opinión de estas personas nunca había sido tomada en cuenta.

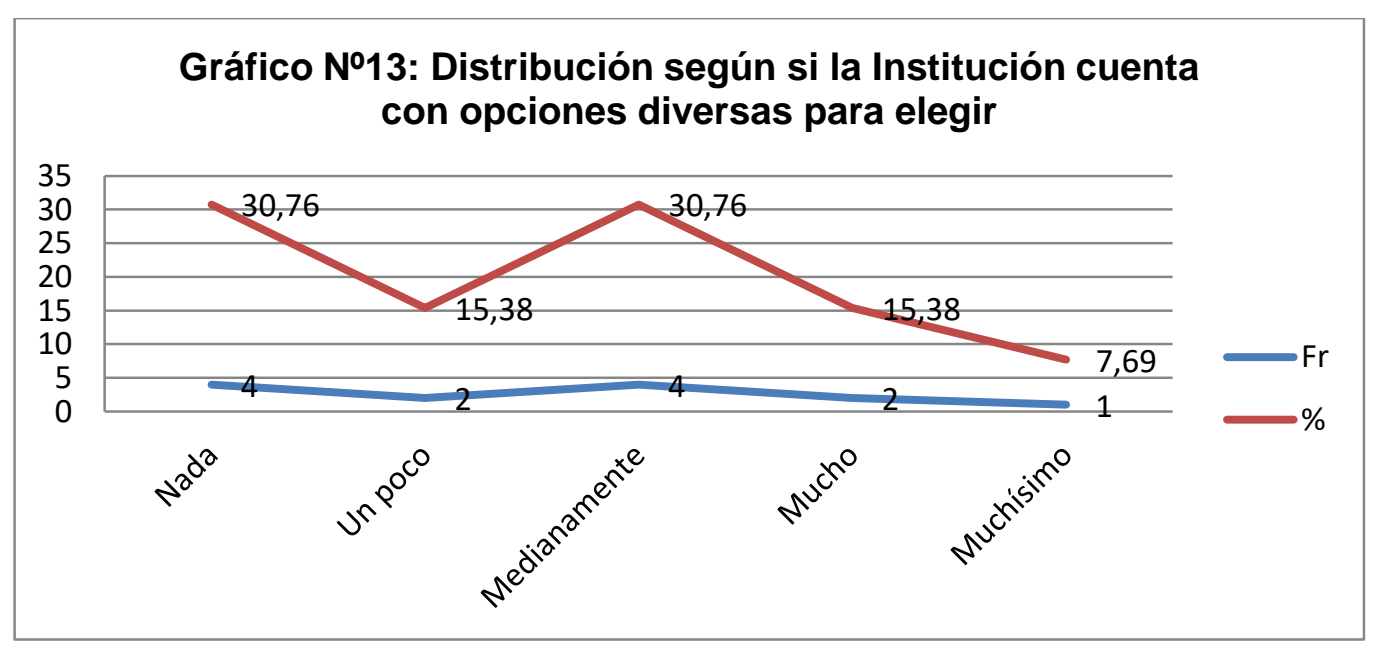


El gráfico 13 nos reporta que el 23.07\% (3 sujetos) afirmó que la institución le ha ofrecido una diversidad de opciones a elegir. En discordancia con esto, el 46.14\% (6 sujetos) declararon que la institución les ha ofertado mediana y poca posibilidad de opciones para su elección, distribuidos en un 30.76\% para la categoría MEDIANAMENTE y $15.38 \%$ para la categoría UN POCO, sumándose a este contexto el que 4 de los sujetos (30.76\%) llegaron a considerar que la institución no les ha ofrecido ninguna opción.

Los datos recolectados revelan disparidad de criterios en los y las adolescentes en cuanto a la motivación que reciben para participar, el conocimiento que tienen sobre el Programa de la Institución y la incorporación de sus propuestas a las actividades programadas. Ahora bien, llama la atención que la mayoría considera que sí se toma en cuenta sus opiniones para la toma de decisiones en su vida, pero que sus opiniones no son tomadas en cuenta por los adultos que toman las decisiones en la institución. Igualmente, piensan que no poseen una diversidad de opciones para elegir.

\section{Componente Acción:}

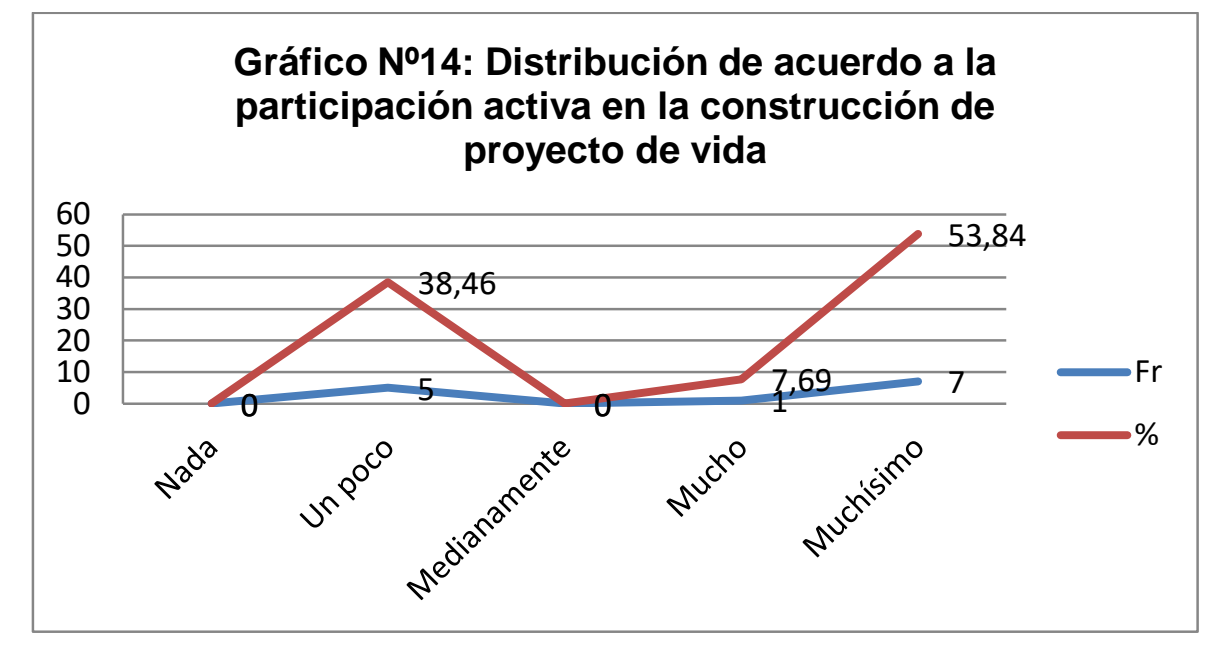

De los 13 sujetos de la muestra, el $53.84 \%$ (7 sujetos) reportó participar muy activamente en la construcción de su proyecto de vida, el $7.69 \%$ (1 sujeto) afirmó que ha participado MUCHO y 5 sujetos $(38,46 \%)$ manifestaron haber participado solo UN POCO en la construcción de su proyecto de vida (Ver Gráfico 14). 


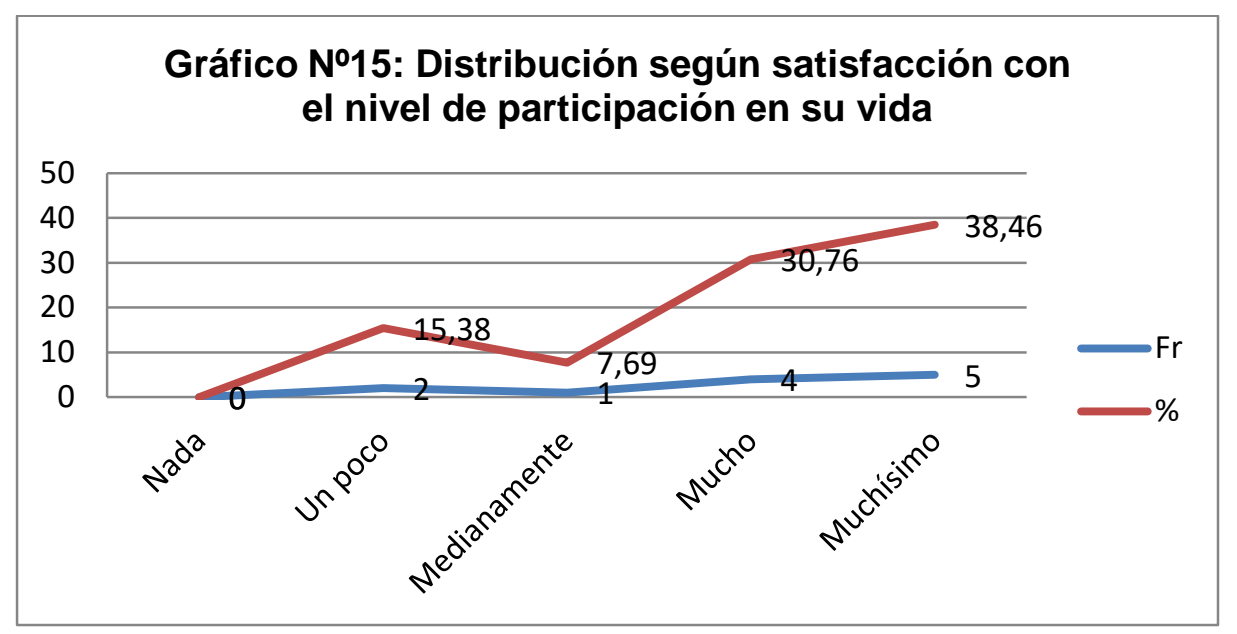

Se reporta que el $69.22 \%$ (9 sujetos) manifestó sentirse satisfecho con el nivel de participación en su vida, distribuidos en $30.76 \%$ en la categoría MUCHO y un $38.46 \%$ en la categoría MUCHÍSIMO. Un 15.38\% (2 sujetos) afirmó sentirse UN POCO satisfecho y un sujeto $(7,69 \%)$ reportó haber estado medianamente satisfecho (Ver gráfico 15).

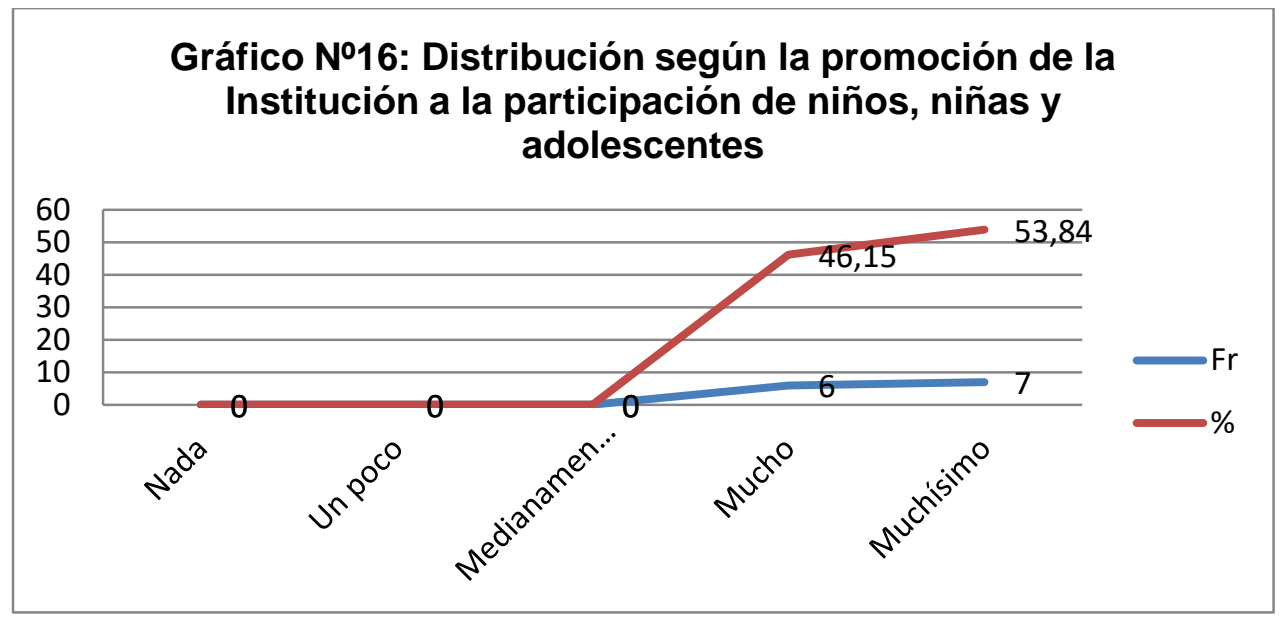

En el gráfico 16 se reporta que el 100\% de la muestra opinó que la institución, en la que se encuentran protegidos, ha estado promoviendo la participación de los niños, niñas y adolescentes, distribuidos en $46.15 \%$ (6 sujetos) para la categoría MUCHO y $53.84 \%$ para la categoría MUCHÍSIMO. 


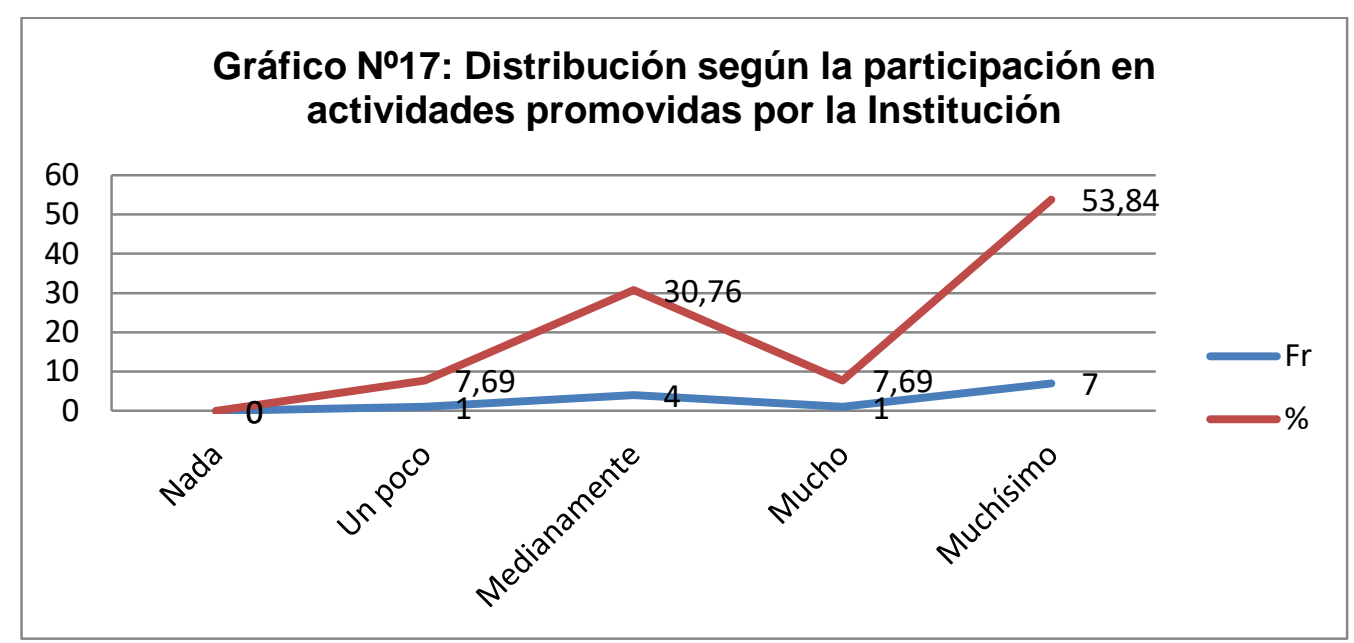

Del total de sujetos de la muestra, 8 (61.53\%) afirmaron haber compartido mucho y muchísimo en las actividades de participación que han sido promovidas por la institución, 7.69\% y 53.84\%, respectivamente. Cinco (5) de los sujetos restantes reportaron que han estado participando medianamente y un poco, 30.76\% y 7,69\%, respectivamente (Ver Gráfico 17).

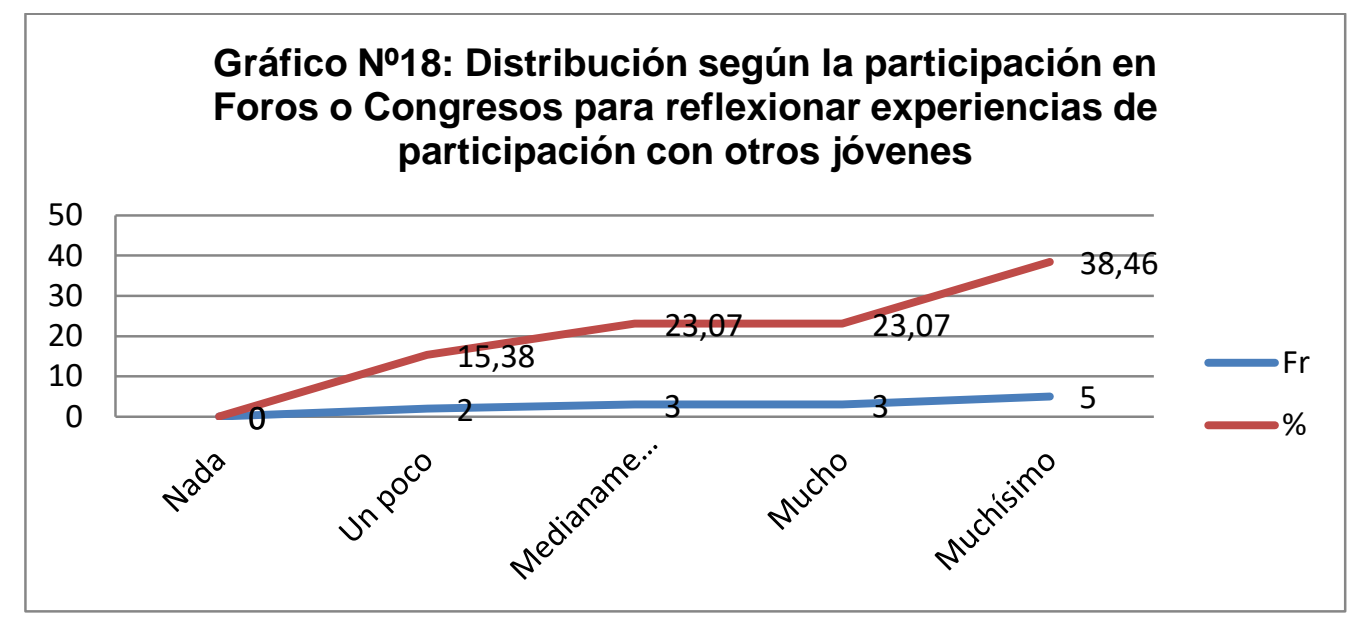

En el gráfico 18 se observa que el $61.53 \%$ (8 sujetos) reportaron haber tenido la oportunidad de compartir en Foros o Congresos para intercambiar experiencias de participación con otros jóvenes de su edad y un 38.45\% (5 sujetos), distribuidos en $23.07 \%$ (3 sujetos) para la categoría MEDIANAMENTE y $15.38 \%$ para la categoría un poco, reportaron haber tenido menos oportunidades para reflexionar e intercambiar experiencias de participación con otros pares adolescentes. 


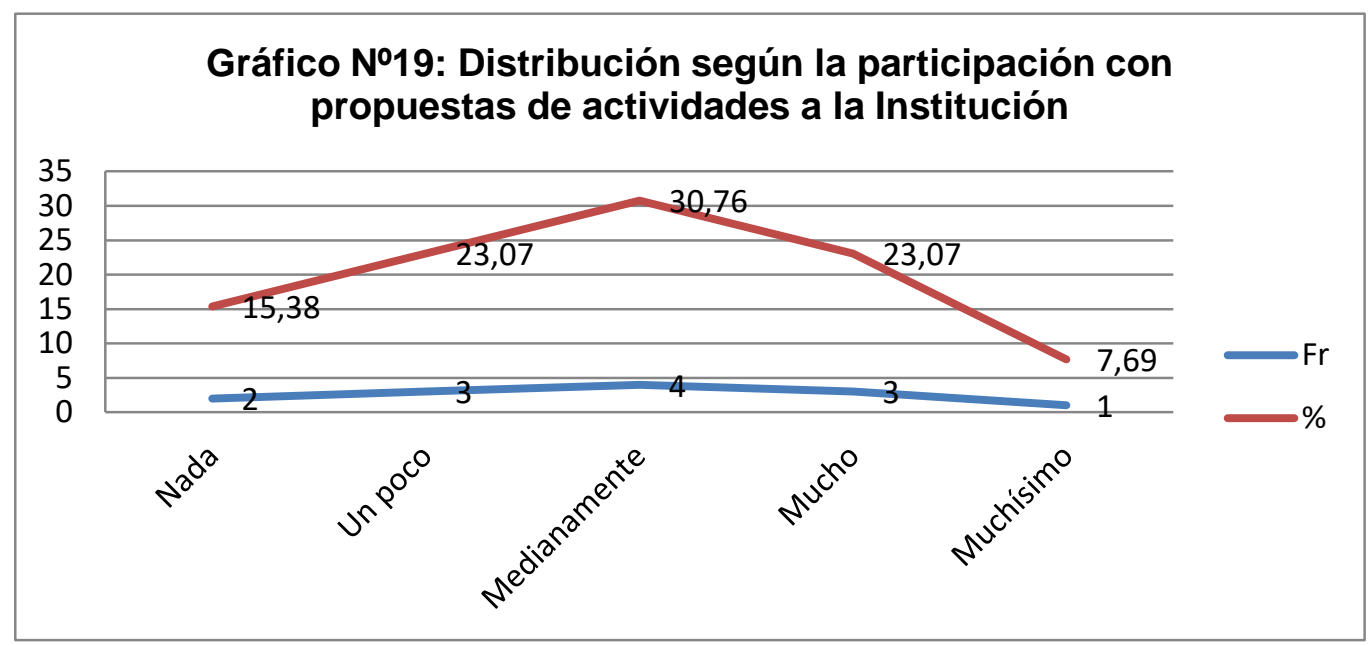

En el gráfico 19 se reporta que el $30.76 \%$ de los y las adolescentes (4 sujetos) afirmaron haber tenido la oportunidad de participar con propuestas de actividades a realizar dentro de la institución. Por el contrario, el 53.83\% (7 sujetos) alegó haber tenido mediana y poca oportunidad de participar en este aspecto, y el 15.38\% (2 sujetos) declararon que sus propuestas de actividades nunca habían sido tomadas en cuenta.

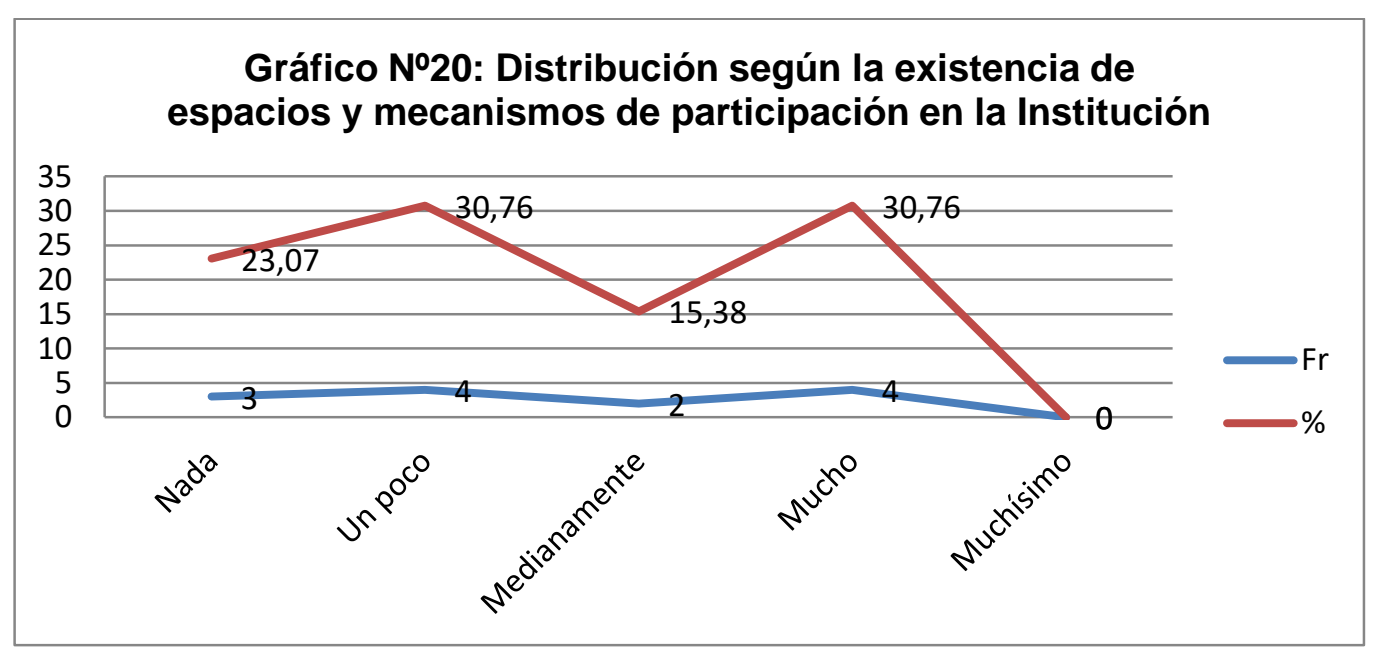

Observamos en el gráfico $\mathrm{N}^{\circ} 20$ que solo un 30,76\% (4 sujetos) consideraron que la institución les ha ofrecido muchos espacios y mecanismos de participación, lo que contrasta con el $46.14 \%$ (6 sujetos) que manifestaron su versión de que la existencia de estos espacios y mecanismos es mediana (15.38\%) y poca (30.76\%). Complementan esta misma tendencia los $3(23.07 \%)$ sujetos restantes para quienes la institución nada les ha brindado en lo que a espacios y mecanismos de participación se refiere. 
Los datos encontrados reflejan que los y las adolescentes consideran tener participación en la construcción de su proyecto de vida y la mayoría están satisfechos con el nivel de participación que han tenido en su vida. Por otro lado, ellos sienten que han tenido la oportunidad de concurrir a distintas actividades relacionadas con su vida cotidiana. Sin embargo, no han sido producto de una decisión personal sino más bien de propuestas realizadas por la institución, ya que la percepción de espacios y mecanismos de participación dentro de la institución es escasa.

\section{La práctica de la participación}

El gráfico 21 nos reporta las respuestas de los y las adolescentes ante la pregunta: enuncie una buena práctica de participación que haya vivenciado en la institución. Merece la pena reseñar que 3 de los sujetos (23.97\%) de la muestra refirieron como buena práctica las actividades recreativas y 2 (15.38\%) mencionaron las actividades de capacitación que han recibido. Por otra parte, hace contraste la reseña que aportaron 7 de los y las adolescentes (53.83\%) cuando informaron que no han asistido (4 sujetos, 30.76\%) a ninguna práctica de participación organizada por la institución o simplemente no se acuerdan (3 sujetos, $23.07 \%)$. Por último, un sujeto (7.69\%) reportó no saber de ninguna buena práctica.

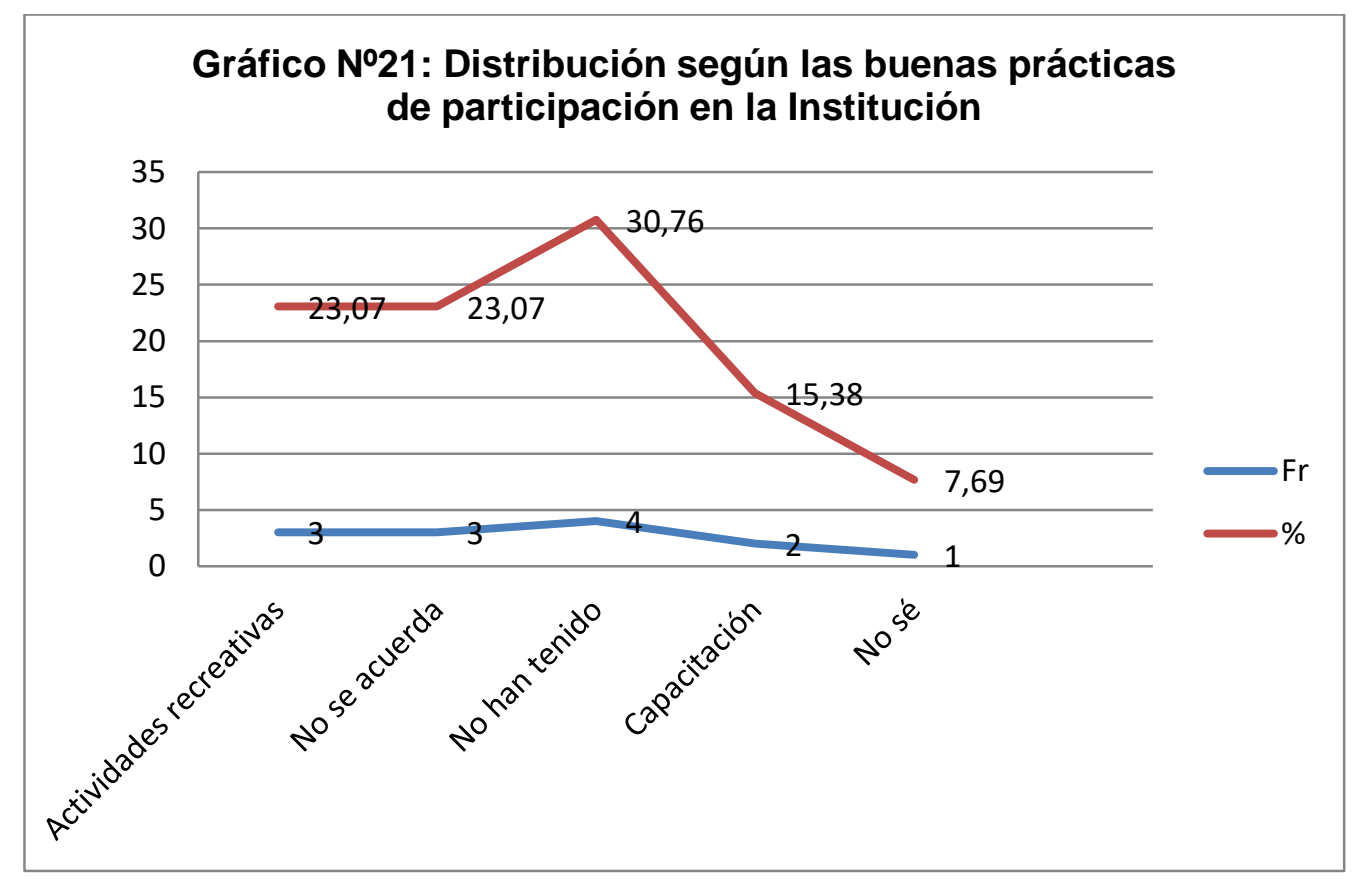

El gráfico 22 reporta las respuestas de los y las adolescentes ante la pregunta: enuncie una propuesta para una buena práctica de participación en la institución. Entre las sugerencias que aportaron, encontramos que 5 sujetos (38.46\%) propusieron actividades 
donde ellos y ellas puedan expresar su opinión y sean escuchados, 2 (15.38\%) propusieron talleres de capacitación para aprender un oficio (un sujeto, para sembrar todo tipo de plantas y otro para prepararse en la carrera de policía). Dos sujetos (15.38\%) recomendaron proyectos deportivos, uno (7.69\%) propuso torneos de video juegos y otro (7.69\%) sugirió talleres que lo apoyen en el modo de pensar y sentir. Vale la pena hacer notar que 3 de los sujetos $(23.07 \%)$ manifestaron no tener ninguna propuesta que recomendar.

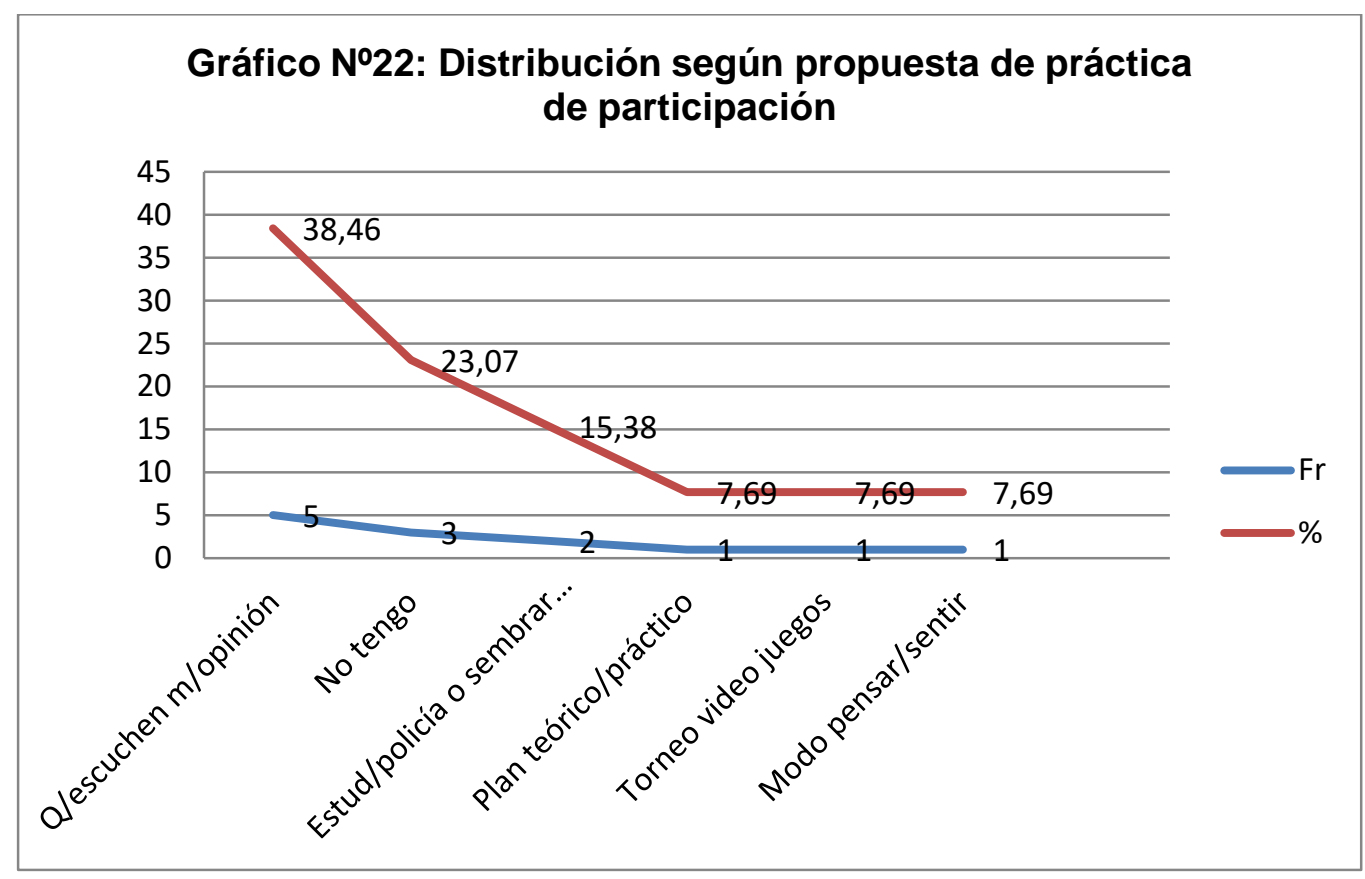

El gráfico 23 nos presenta un mapa de los intereses manifestados por los y las adolescentes para un Programa de Desarrollo Personal. Los temas mayormente elegidos fueron: autoestima ( 7 sujetos, $53.84 \%$ ) y sexualidad ( 6 sujetos, $46.15 \%$ ). En menor proporción autoconocimiento (3 sujetos, 23.07\%), liderazgo (2 sujetos, 15.38\%) y deportes (2 sujetos, $15.38 \%$ ). Entre otros temas, enunciados de manera individualizada, encontramos: proyecto de vida, derechos, personalidad, pautas para hacer la vida más fácil y primeros auxilios. Es importante resaltar que el porcentaje excede el $100 \%$, ya que fueron tomadas las respuestas individuales de cada uno de los participantes. 


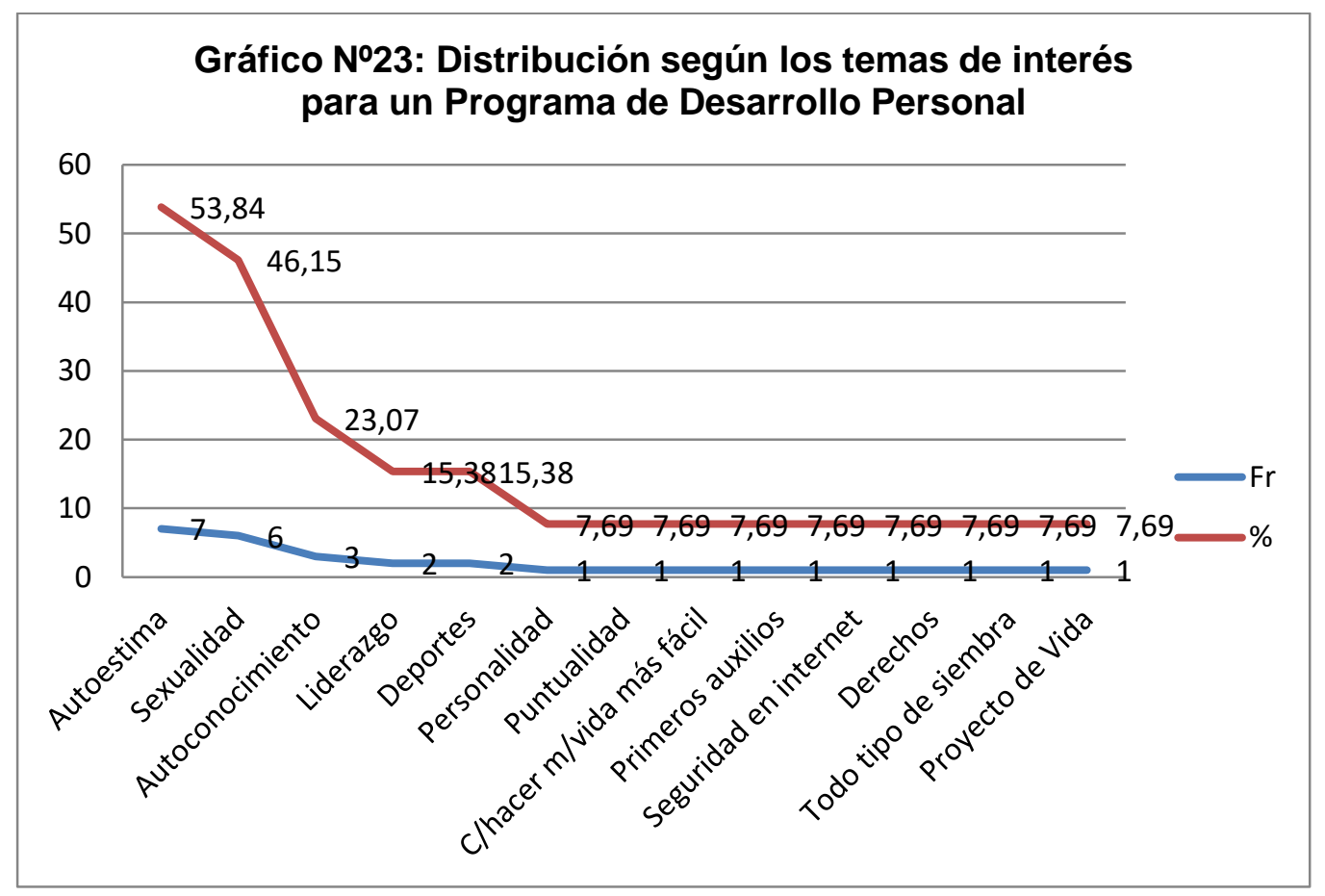

Se puede observar que los niños, niñas y jóvenes reportan como buenas prácticas las relacionadas con actividades recreativas y demandan a la institución que sus opiniones y/o sugerencias sean tomadas en cuenta para acciones participativas. Asimismo, es interesante señalar que los temas manifestados por ellos como interesantes están relacionados con Crecimiento y Desarrollo Personal. Ciertamente conocerse, capacitarse y adquirir competencias para su formación personal y para la vida es de especial interés, sobre todo a la hora de ponerlo en práctica con la desinstitucionalización.

\section{Conclusiones y recomendaciones}

Esta investigación se centró en la perspectiva de los y las adolescentes institucionalizados respecto a la participación, analizada desde tres dimensiones: opinión, toma de decisiones y acción. Cualquier conocimiento, motivación o instrumento derivado de este ejercicio investigativo debe impulsar acciones dirigidas hacia niveles superiores de competencia participativa, contribuyendo así a la mejora de la calidad de vida de los NNA institucionalizados que deben tener acceso a las mismas oportunidades que los no institucionalizados.

Los resultados obtenidos ponen de manifiesto la importancia de la capacitación de los diferentes grupos de interés para preparar y llevar a cabo una participación infantil efectiva (Corona y Morfín, 2001, pp. 95-111), y un freno a la pretensión adulta de que los niños y niñas 
se adapten a los requisitos definidos por el diseño adulto-céntrico de las actividades (Trilla y Novella, 2001).

Este estudio requiere de aportes adicionales que complementen y enriquezcan sus resultados. Contribuir a la implementación generalizada de la CDN requiere de una línea de investigación sobre la institucionalización de la participación en las diferentes estructuras sociales a favor de la generación de una cultura de la participación infanto-juvenil.

Se cuenta con esfuerzos para garantizar el derecho a la participación de NNA. Se ha notado mejoría en la calidad de los entornos y de los programas, ya que contribuyen con su conocimiento y experiencias para hacer visibles las problemáticas que los rodean, pero continuamos con el desafío de incluirlos en aspectos que tienen que ver con su vida cotidiana.

La inexistencia de reglas definidas que potencien el acto de la participación termina por convertirse en una simple actividad que el niño practica bajo la supervisión del adulto educador. Se recomienda capacitación de ambos para obtener el mejor provecho de la relación niño-adulto en la vida cotidiana.

Los NNA tienden a responder a los instrumentos y a las entrevistas para complacer y no queda claro hasta qué punto comprenden lo que se les está preguntando. Se observó dificultad de comprensión que el término participación generó. Se manifiesta la necesidad de un proceso de participación infantil integrado desde el ingreso, la estadía y hasta la finalización del servicio de protección.

Hemos visto a través de sus opiniones la necesidad de escucha, ser tomados en cuenta, ser parte de decisiones que los afectan, tener opciones para elegir y proponer. Todo ello incide en la formación de su identidad individual y social, al desarrollarse las competencias necesarias para que sean seres con autonomía y responsables.

La garantía de la participación activa aumenta la eficacia de acciones, corresponsabilidad, sentido de pertenencia y disminuye la marginalización. Los estudios centrados en la percepción de los NNA enfatizan la importancia que tiene para ellos ser tomados en cuenta ante las diversas dinámicas sociales. Por lo tanto, los proyectos deben visibilizar sus requerimientos y poner de manifiesto las alternativas de participación demostradas a través del acercamiento real con las instituciones involucradas.

Cada vez son más los NNA que reclaman espacios y mecanismos de participación en todas las esferas relacionadas a su vida, desean participar en la toma de decisiones y en la ejecución de actuaciones de su entorno, conocer y practicar sus derechos y deberes, pertenecer a una comunidad y que esta lo identifique como parte de ella. El reto es seguir realizando investigaciones participativas, generar conocimiento, trabajar de forma 
colaborativa y proponer alternativas que garanticen de manera coherente la participación activa de los niños, niñas, los y las adolescentes, de los cuales somos todos responsables.

Hacer referencia a los Derechos Humanos de los NNA significa reconocer, respetar y garantizar su personalidad individual, en tanto titular de derechos y obligaciones. Por ello, no solo es brindar cuidado y protección, sino que es fundamental la opinión del niño, de modo que se exprese en asuntos de su interés y que sea tomado en cuenta.

\section{Referencias bibliográficas}

Acosta, A. (2007) Educación Inicial: Fundamento del Desarrollo infantil y del desarrollo humano. Revista Javeriana. La Universidad en diálogo con el mundo. Educación. Número 733. Tomo 143, Año 74. Bogotá: Pontificia Universidad Javeriana. JAVEGRAF, 145-173.

Acosta F., Barbosa D., (2005) Participación, organización y ciudadanía juvenil. IV Simposio Nacional de Investigación y Formación en Recreación. Vicepresidencia de la República / Coldeportes / FUNLIBRE. Mayo 19 al 21 de 2005. Cali, Colombia.

Allan Dale, R. (1999, octubre): Participación Infanto-Juvenil: Un reto social. Organización Panamericana de la Salud/ Organización Mundial de la Salud.

Carli, S. (2012). Niños y niñas como sujetos sociales y políticos. Segunda Escuela internacional de la Red de Posgrados en Infancia y Juventud: Democracia, Derechos humanos y ciudadanía: infancias y juventudes en América Latina y el Caribe, Montevideo. Recuperado en: https://oei.org.uy/historico/clacso.php

Corona, Y. y Morfín, M. (2001). Diálogo de Saberes sobre Participación Infantil. México: UNAM, UNICEF, COMEXANI. Recuperado en: http://www.uam.mx/cdi/dialogo/plegal.pdf

Crowley, P. (1998). Participación infantil: para una definición del marco conceptual. En: La participación de niños y adolescentes en el contexto de la Convención sobre los derechos del niño: visiones y perspectivas. Florencia: UNICEF.

Encovi (2017). Encuesta sobre condiciones de vida en Venezuela. Caracas: UCAB, USB Lacso.

Espinar, A. (2002) El Ejercicio del Poder Compartido. Save the Children Suecia: Estudio para la elaboración de indicadores e instrumentos para analizar el componente de participación de niños y niñas en proyectos sociales. Lima: Escuela para el Desarrollo. 
Flekkoy, M. G., \& Kaufman, N. H. (1997). The Participation Rights of the Child: Rights and Responsibilities in Family and Society. London: Jessica Kingsley.

Hammarberg, T. (1998). La escuela y los derechos del niño: la significación de la Convención de los Derechos del Niño en el campo de las nuevas políticas educativas. Florencia: UNICEF (Innocenti Lectures).

Hart, R. (1992). Children's Participation: From tokenism to citizenship, Innocenti essays, no. 4, Florencia: Centro Internacional para el Desarrollo del Niño del UNICEF, 1-39-

Hart, R. (1993). La Participación de los Niños: de la Participación Simbólica a la Participación Auténtica. Santa Fe de Bogotá: UNICEF TACRO.

Invernizzi, A., \& Milne, B. (Eds.) (2005). Children's citizenship: an emergent discourse on children's rights of the child? [Sección especial]. Journal of Social Sciences, 9, 8399.

Kjorholt, A. T. (2008b). Children as New Citizens: In the Best Interest of the Child? En A. James \& A. L. James (Eds.), European Childhood. Cultures, Politics and Childhoods in the European Union (pp. 14-37). Basingstoke: Palgrave Macmillan.

Konterllnik I., (2000). La participación de los adolescentes ¿Exorcismo o construcción ciudadana? En Tenti Fanfani, Emilio (comp.) Una escuela para los adolescentes. (pp. 79-108). Buenos Aires: UNICEF/Losada.

Laje, M. I. y Cristini, M. R. (2010). Elementos teóricos para el análisis. En Inversión pública en niñez y juventud. Profundizando compromisos y sensibilización de la UNC respecto de los derechos en niños/as y jóvenes. Córdoba: Secretaría de Extensión Universitaria, Universidad Nacional de Córdoba - Unicef - Fundación Arcor.

Lister, R. (2003). Acquiring Responsibilities and Citizenship: Social Participation and Social Responsibilities. En L. Chisholm (Ed.), Family forms and the young generation in Europe. (pp. 95-103). Vienna: Osterreichisches Institut fur Familienforschung.

Liebel, M. (2007). Paternalismo, participación y protagonismo infantil. En Participación Infantil y Juvenil en América Latina (1era ed.) (pp. 113-146). México: Universidad Autónoma Metropolitana.

Pilotti, M. A., (2004). Los Paradigmas sobre la Infancia y la Adolescencia y el Trabajo Social. Revista Conciencia Social (4) 5. Córdoba: Escuela de Trabajo Social. Universidad Nacional de Córdoba.

Redhnna. (s/f). (Red por los Derechos Humanos de Niños, Niñas y Adolescentes) Información EPU - REPUBLICA BOLIVARIANA DE VENEZUELA Situación de los Derechos de Sectores Específicos: Niños, Niñas y Adolescentes. 
https://lib.ohchr.org/HRBodies/UPR/Documents/session12/VE/JS12-REDHNNAJointSubmission12-spa.pdf.

Smith, A. B., y Bjerke, H. (2009). Children's citizenship. En N. J. Taylor y A. B. Smith (eds.), Children as citizens? International voices. (p. 15-34). Dunedin: Otago University Press.

Trilla, J. y Novella A. (2001). Educación y participación social de la Infancia. Revista Iberoamericana de Educación. No. 26, mayo-agosto, 137-164.

Viñar, M. (2009). Mundos adolescentes y vértigo civilizatorio. Montevideo: Trilce.

Zanabria, M., Fragoso, B. \& Martínez, A. (2007). Experiencias de participación infantil en Tlaxcala y Ciudad de México. Tramas, 28, 121-140.

\section{Otros documentos consultados}

Cecodap (2011). Informe Somos Noticia de CECODAP período Octubre 2010 a Septiembre de 2011. CECODAP: Caracas.

Comité de los Derechos del Niño. (2009). Observación General № 12: El derecho del niño a ser escuchado. CRC/C/GC/12. 20 de julio de 2009.

Convención sobre los derechos del niño, resolución 44/25 (1989).

ONU. (1989). Organización de Naciones Unidas: Convención sobre los derechos del niño, resolución 44/25.

FONDENIMA. (2012). Informe de la Fundación Oficina Nacional de Denuncia del Niño Maltratado, período trienio 2007- 2012. Caracas.

PANACED. (2012). Programa de Atención de Niños y Adolescentes en Circunstancias Especialmente Difíciles. Informe del período 2010-2012. Barquisimeto, Estado Lara, Venezuela.

Red Latinoamericana de Acogimiento Familiar. [RELAF]. (2011). Niñez y adolescencia institucionalizada: visibilización de graves violaciones de $\mathrm{DDHH}$. Serie: Publicaciones sobre niñez sin cuidados parentales en América Latina: Contextos, causas y respuestas. Buenos Aires. Disponible en: https://www.relaf.org/Documento\%20agosto\%202011\%20Relaf.pdf

Save the Children. (2004). Participación de los NNA a 15 años de la CDN.

UNICEF. (2003). Informe del Estado Mundial de la Infancia. UNICEF. Programa Regional para América Latina y El Caribe. 
UNICEF. (2006). Argumentos y herramientas para contribuir a la inversión social a favor de los adolescentes de América Latina. UNICEF. Ciudad de Panamá, Panamá.

UNICEF. (2008). Desarrollo positivo adolescente en América Latina y el Caribe. Panamá: UNICEF. 